Universidad de Lima

Facultad de Comunicación

Carrera de Comunicación

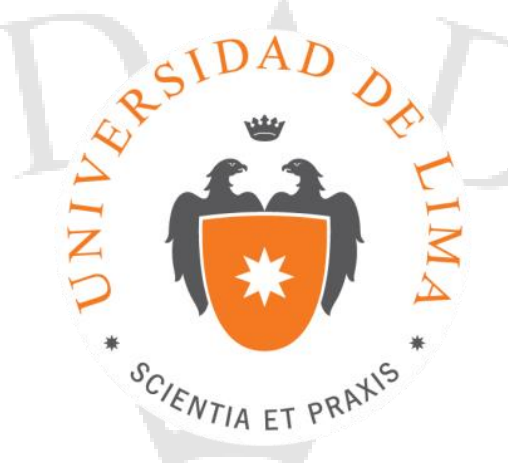

\title{
PERCEPCIÓN E IMAGEN DEL CENTRO COMERCIAL PLAZA NORTE
}

Trabajo de investigación para optar el Título Profesional de Licenciado en

Comunicación

\section{Claudia Mónica Evanan Paniagua}

Código 20101520

\section{Asesora}

María Luisa Arrieta Clavijo

$$
\text { Lima - Perú }
$$

Julio de 2016 


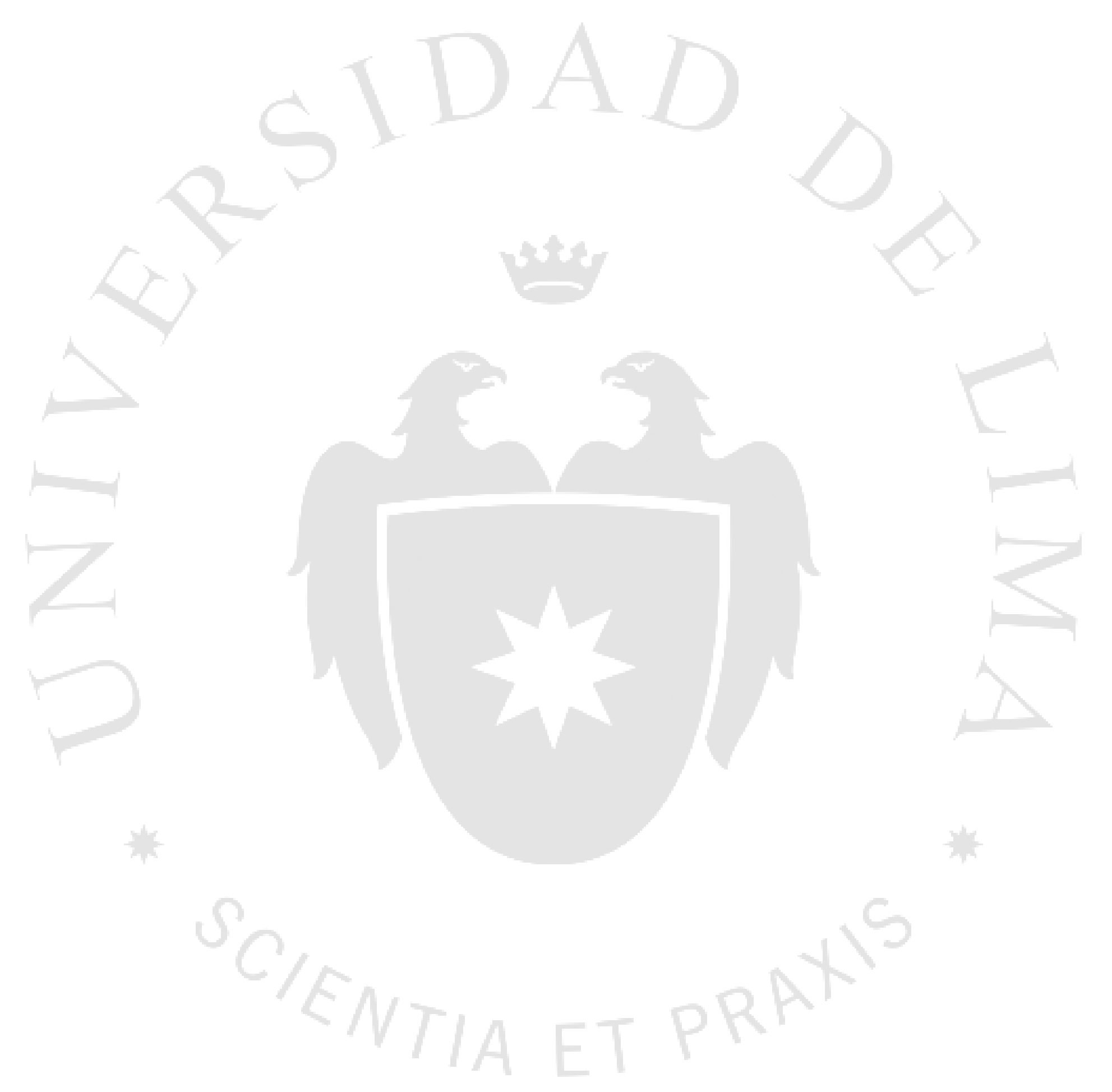



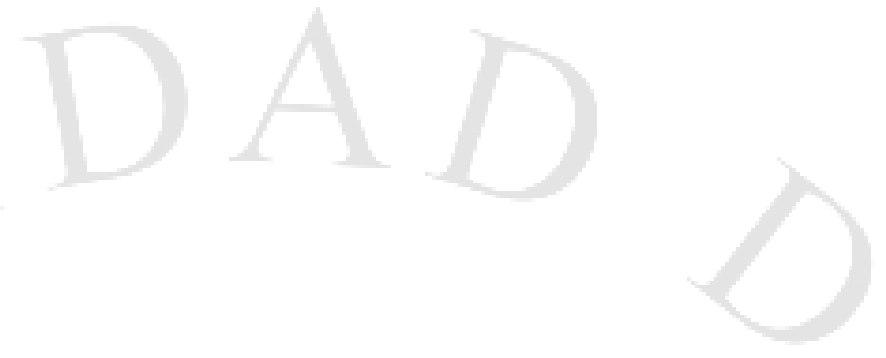

PERCEPCIÓN E IMAGEN DEL CENTRO COMERCIAL PLAZA NORTE 


\section{ÍNDICE}

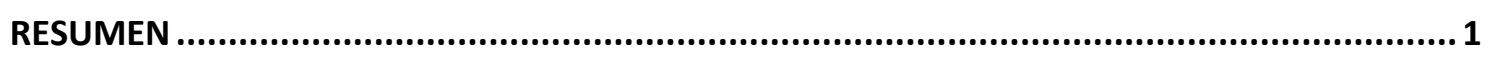

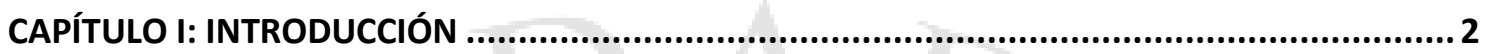

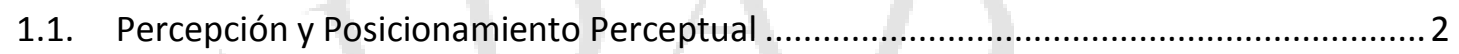

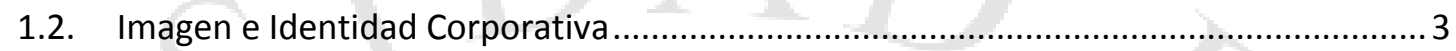

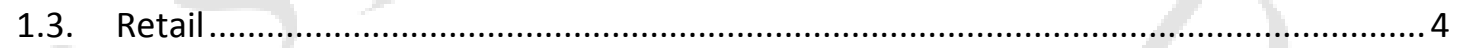

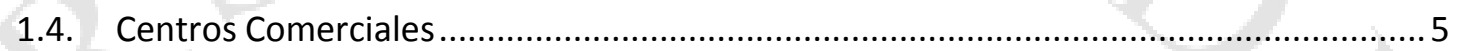

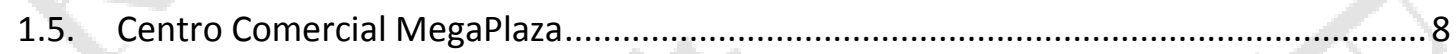

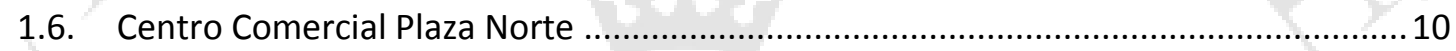

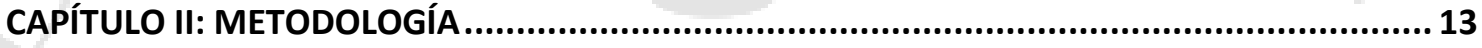

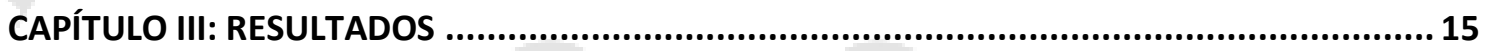

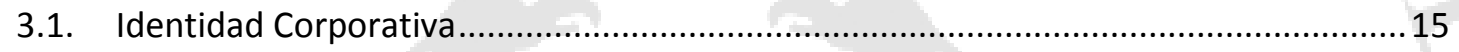

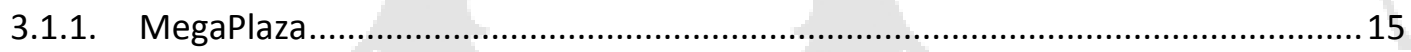

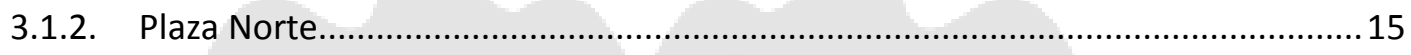

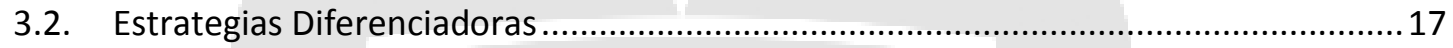

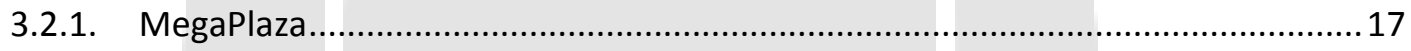

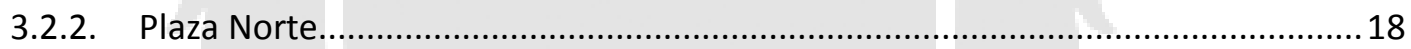

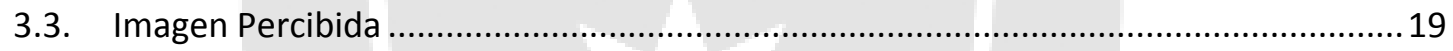

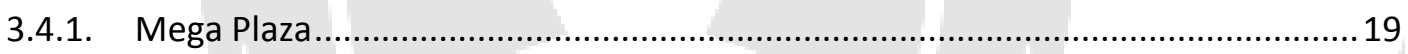

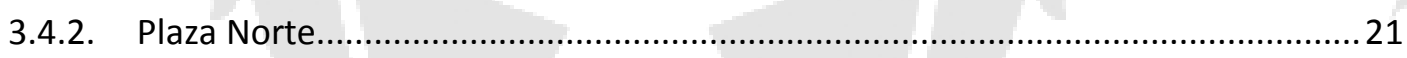

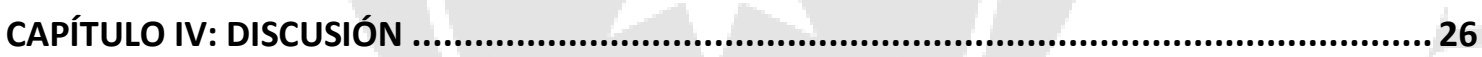

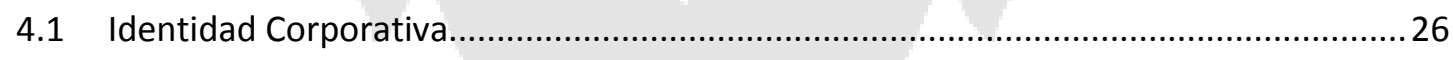

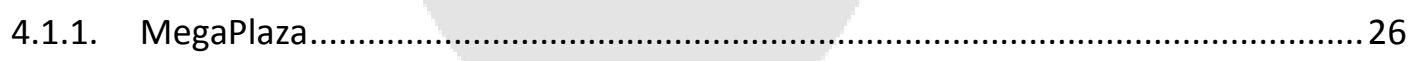

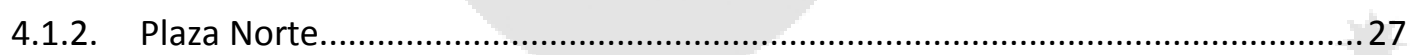

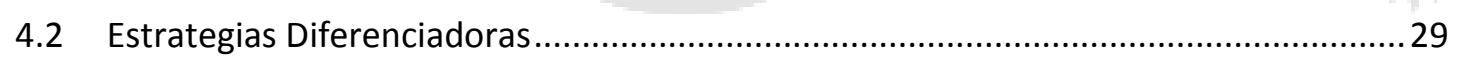

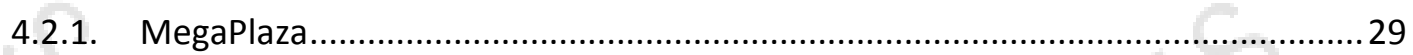

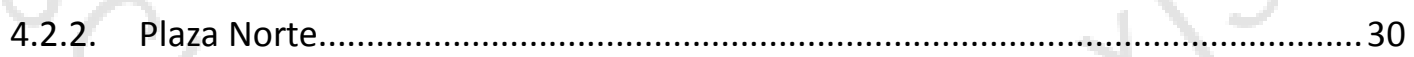

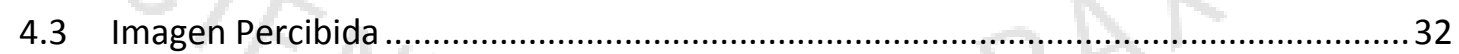

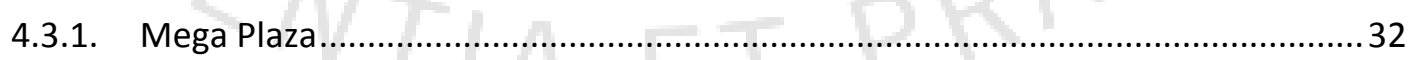

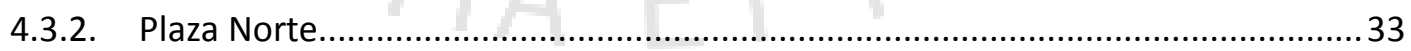

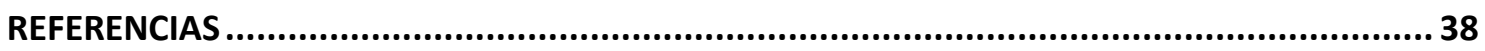

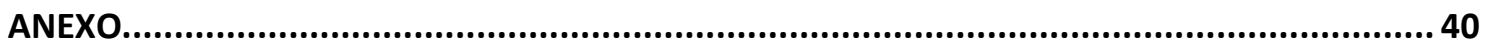

ANEXO 1: FICHA TÉCNICA ENTREVISTA EJECUTIVOS CENTROS COMERCIALES ......................41

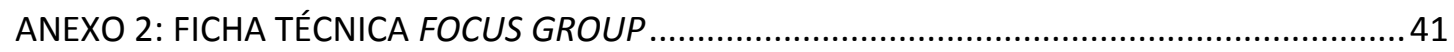


ANEXO 3: FICHA TÉCNICA ENCUESTA

42

ANEXO 4: RESUMEN EJECUTIVO ENCUESTA

.42

ANEXO 5: GUÍA PREGUNTAS EJECUTIVOS CENTROS COMERCIALES

.43

ANEXO 6: GUÍA FOCUS GROUP

.44

ANEXO 7: CUESTIONARIO PLAZA NORTE

.46

ANEXO 8: SERVICIOS QUE RECUERDA.

.48

ANEXO 9: ELEMENTOS QUE VALORA

48

ANEXO 10: RESPUESTA DIFERENCIAL SEMÁNTICO

49 


\title{
RESUMEN
}

A lo largo de los últimos años, la ciudad de Lima ha experimentado un crecimiento rápido en la oferta de los centros comerciales, produciendo importantes transformaciones en el rubro y en la manera cómo el público los percibe. La cantidad de malls construidos al año 2014 fomenta que cada uno busque un camino para diferenciarse; más aún si la competencia directa se encuentra tan cerca. El Centro Comercial Plaza Norte propone una oferta no solo comercial sino de recreación que se diferencia de las ofertas planteadas por los demás centros comerciales que existen en Lima. Su propuesta se basa en un enfoque sociocultural que integra la carga social de su público objetivo con conceptos creativos para atraerlos. El presente trabajo de investigación pretende determinar la percepción e imagen actual, año 2014, que se forma entorno al Centro Comercial Plaza Norte. Por consiguiente, se realizaron entrevistas a profundidad, focus group y encuestas como instrumentos de medición. Del estudio realizado se desprende que los visitantes de mencionado mall no perciben, al instante, las diferencias que existen entre Plaza Norte frente a los demás centros comerciales, ni a su competencia directa: MegaPlaza. Sin embargo, al proveerles una lista con los elementos únicos, el público lo reconoce como un centro comercial innovador teniendo como mayores puntos de exclusividad su Gran Terminal Terrestre y Teatro Plaza Norte.

\section{Palabras Claves}

Retail, Centros Comerciales, Percepción, Identidad, Plaza Norte

\begin{abstract}
«Confieso que la primera vez que vi un mall, en Miami, pensé que era una idea excelente: se creaba un gueto para quienes quisieran ir a las tiendas a comprar y se liberaba a las ciudades de la invasión de las tiendas que las afeaban. No me percaté de que la gente iría al mall no sólo a comprar, sino también para pasear, para quedarse a vivir allí. Esto es un hecho: la gente ya no se reúne en las plazas, van al centro comercial, que es donde se desarrolla nuestra vida pública. En el centro comercial no pasa nada. Nuestros antepasados acudian a las cavernas para defenderse de la intemperie y de las fieras. Mutatis mutandis, esto es lo que sucede ahora: en el centro comercial uno se siente seguro, a salvo: ni siquiera hay que comprar, lo principal es que estés allí, que te acostumbres a encontrar en ese lugar la posibilidad de que todos tus deseos pueden ser satisfechos y, naturalmente, tus deseos bajan mucho de nivel».
\end{abstract}

Entrevista a José Saramago, El Cultural, 27-12-2000. 


\section{CAPÍTULO I: INTRODUCCIÓN}

\subsection{Percepción y Posicionamiento Perceptual}

Rivera, Arellano, \& Molero (2013) definen que la percepción es la imagen mental que se forma con ayuda de la experiencia y de las necesidades; resultado de un proceso de selección, interpretación y corrección de sensaciones. Según los autores se caracteriza por ser subjetiva, selectiva y temporal. Subjetiva, debido a que las reacciones de un individuo a otro varían dependiendo de sus necesidades en ese momento o experiencias. Selectiva, ya que una persona no puede percibir todo al mismo tiempo, por lo que selecciona su campo perceptual en función de lo que desea percibir. Temporal, porque es un fenómeno a corto plazo y evoluciona a medida que se enriquecen sus experiencias, o varían sus necesidades y motivaciones.

De acuerdo a Solomon (2008) el consumidor al momento de percibir absorbe sensaciones que después utiliza para interpretar el mundo que lo rodea. Las sensaciones son respuestas inmediatas de nuestros receptores sensoriales (ojos, oído, nariz, boca, tacto) a estímulos básicos como la luz, el color, el sonido, los olores y la textura. Por lo tanto, la percepción es el proceso en el cual las personas seleccionan, organizan e interpretan tales sensaciones.

Arellano (2002) enuncia la percepción como la forma en que el individuo observa el mundo que lo rodea. Agrega que la percepción del consumidor determinará otro tipo de respuestas: cognitivas, afectivas y conductuales. Cognitivas: creencias acerca del producto, expectativas sobre el rendimiento o funcionamiento del producto. Afectivas: referidas a la motivación de compra, actitudes hacia el producto, preferencia de marca. Conductuales: intención de compra, compra efectiva, lealtad a la marca, rechazo, adopción de la marca, entre otros.

El Posicionamiento perceptual ligado a un producto se interpreta en base a lo que ya se sabe acerca de su categoría y de las características de las marcas existentes. 
Dentro de la percepción de una marca se incluyen los atributos funcionales que son sus características como precio, contenido, etc., así como sus atributos simbólicos (su imagen de lo que creemos que se dice de nosotros cuando lo usamos). Nuestra evaluación de un producto usualmente es el resultado de lo que significa, y no de lo que hace. Este significado es el que constituye la posición de mercado del producto o marca y puede estar más relacionado con lo que esperamos del desempeño del producto según lo comunica el color, empaque o estilo, más que con el producto en sí (Solomón, 2008).

\subsection{Imagen e Identidad Corporativa}

Según Kenneth (1956) los seres humanos nos guiamos por imágenes que percibimos más que por conocimiento o información. No solemos reaccionar a lo que es verdad sino a lo que creemos que es verdad, para lo cual usamos valores subjetivos y conocimiento para mediar entre nosotros y el mundo que nos rodea. Por ello nuestra conducta está, casi todo el tiempo, guiada por lo que percibimos.

La imagen en el ámbito corporativo es una representación mental, estructura o esquema mental de asociaciones que un público asocia a un objeto -organización, marca, producto servicio- (Capriotti, 2009). Pintado \& Sánchez (2013) agregan que se manifiesta internamente. La representación mental la realiza cada individuo, por tanto, la imagen que una persona tenga de una empresa puede ser totalmente diferente a la que tenga otra.

Suele ser habitual confundir "identidad corporativa" con "imagen corporativa". La identidad corporativa hace referencia a lo que la empresa comunica a sus públicos, partiendo de lo que es: su esencia; es decir, la serie de atributos que lo hacen identificadores y diferenciadores. En este sentido se tiene en cuenta: la historia de la compañía, el proyecto empresarial, la cultura corporativa (Pintado \& Sánchez, 2013).

La historia de la compañía, desde su fundación hasta el presente, momentos positivos como negativos, asociación con productos o servicios pioneros, transformaciones introducidas en el mercado, perfil del cliente, éxitos y fracasos de las 
personas que han trabajo ahí. El proyecto empresarial, relacionado con el momento presente de la compañía y hace referencia a: la filosofía de la empresa, sus valores; su estrategia corporativa; y los procedimientos de gestión utilizados en las diferentes áreas funcionales. La cultura corporativa, comportamientos o formas de hacer las cosas, valores compartidos en la empresa, hace referencia tanto al presente como al pasado (Pintado \& Sánchez, 2013).

\subsection{Retail}

Stanton, Etzel, \& Walker (2007) consideran que el retail implica la comercialización de bienes y servicios al público, sea este consumidor final o de comercio. Sus principales establecimientos son las tiendas por departamento, supermercados, tiendas de descuentos, entre otros; todos ellos presentes en un centro comercial. Para Rubén Rico \& Evaristo Doria (2005) el negocio minorista en el mundo real compite en base a precios; sin embargo, sugieren que lo mejor es brindar un ambiente confortable y ofrecer experiencias inolvidables.

Existen dos maneras de crear experiencias en el retail según Doug Stephens (2013), experiencias totalmente automatizadas y experiencias totalmente animadas. La primera, está guiada por tecnología de punta operada por personal altamente capacitado. Produce una experiencia personalizada que permite al cliente encontrar el producto exacto que fue a buscar. Se busca brindar experiencias a través de alta tecnología donde estas priman sobre el acercamiento humano. El segundo tipo de experiencia, se refiere a personal altamente capacitado que ayudará al cliente a optar por la opción que mejor le favorezca. En este caso, es el representante de marca acompañado de excelente tecnología quien ejercerá influencia sobre el público.

La innovación es uno de los factores más importantes en el retail según considera Arellano (2002), quien observa que la empresa que no innova tiende a quedar obsoleta y a desaparecer. Por ello la creación y desarrollo de nuevos productos se torna una actividad indispensable. El mismo autor define el término innovación como "una 
idea, práctica o artefacto material considerado como nuevo por el consumidor quien lo adopta". Sin embargo, el grado de novedad puede variar desde una novedad absoluta en el mercado hasta un mejoramiento de un producto existente. Luecke (2004) considera que existen dos categorías de innovación. La innovación incremental, que se suele interpretar como la explotación de las formas o tecnologías ya existentes, hay una mejora a algo que ya existe o se modifica una forma o tecnología ya existente para servir a otro fin. La innovación radical, por el contrario, es algo nuevo para el mundo y un progreso con respecto a una tecnología o metodología ya existentes.

\subsection{Centros Comerciales}

López (1999) plantea que un centro comercial es un conjunto de tiendas con una arquitectura y diseño común que surgió a mediados del siglo XX en EE.UU. Originalmente se quiso imitar un centro urbano como réplica artificial de una plaza, con comercios y restaurantes: un lugar donde la gente pasea, se divierte y compra, pero con las modernas comodidades. De esta manera, los centros comerciales avanzaron hacia la sofisticación.

Actualmente se han convertido en espacios de refinada arquitectura y con complicados diseños. Son áreas de esparcimiento de interacción social, con alegres fuentes, atractivos corredores, cómodas bancas alrededor de los puntos de reunión. Son espacios públicos en los que se atrae mediante la música, los olores y las texturas de forma que todos estos elementos forman un ambiente agradable, expresivamente fantástico. Es parte de la hiperrealidad donde estas construcciones fantásticas superan a lo original, a lo auténtico (López, 1999). Los centros comerciales son y pretenden, señala la misma autora, espacios de vida cotidiana, de manera que los edificios, objetos que los adornan, la publicidad y el crédito ayudan a crear un ambiente virtual: entre la realidad y la fantasía.

León-Gambetta (2016) señala que los centros comerciales "modernos" son establecimientos manejados por un solo operador cuyo fin es vender. Underhill (2004) 
añade que deben contar con estacionamiento; además, que los centros comerciales fueron creados para pasar largas horas, por lo que ofrecen una gran cantidad de alternativas. El tamaño y orientación es determinado por las características del mercado donde influenciará. Se pueden identificar tres tipos: malls, centros comerciales abiertos y centros comerciales híbridos (León-Gambetta, 2016).

El formato mall es un centro comercial cerrado de gran extensión, con temperatura e iluminación controladas. Suelen contar con 1 ó 2 tiendas anclas. Ofrecen servicio de diferente tipo y variedad. Sus tiendas están conectadas por pasillos, cuentan con varias entradas de ingreso. Además, su estacionamiento se encuentra dentro del mismo centro comercial. De este formato existen dos tipos: centro comercial regional y centro comercial súper-regional -más extenso, mayor número de tiendas anclas y niveles que el regional- (León-Gambetta, 2016).

El formato centro comercial abierto, sus tiendas están ubicadas en forma lineal, de L, U, e incluso Z. No cuentan con pasajes que comuniquen sus tiendas. No cuentan con tiendas anclas, y si llegan a tener máximo es una. En este formato existen los tipos centros comerciales abiertos comunitario, vecinal, power center, con temática específica, outlets y strip center (León-Gambetta, 2016).

Benavides (2013) agrega que existen dos factores importantes en un centro comercial. Estos son tangibles e intangibles. Los tangibles son aquellos elementos inherentes del mall que estuvieron planificados desde el comienzo del proyecto tales como la infraestructura, tenat mix (distribución o mezcla ideal de tipos de tienda o locales que se encuentran en un centro comercial), facilidad en el acceso, capacidad de estacionamiento. Sin embargo, estos factores pueden ser copiados por la competencia. Estos elementos tangibles consiguen compras impulsivas a corto plazo, mas no una proyectada a largo plazo que conlleva a la fidelidad del consumidor.

El factor intangible es aquel que se relaciona más con las experiencias, las emociones. Así se encuentran elementos como la belleza, la comodidad, el sentido de pertenencia. Si estos elementos son trabajados correctamente se convertirán en parte de la identidad única y diferenciadora del centro comercial frente a la competencia (Benavides, 2013). El mismo autor añade que se requiere trabajar en este elemento regalando experiencias vinculadas al posicionamiento que logren ser grabadas en la memoria del cliente como original y único. Si se logra hacerlo bien se podrá vincular 
emocionalmente al cliente y se podrá fidelizarlo realmente, por lo que se conseguirá afluencia y compra a largo plazo. El fin es "convertir a los centros comerciales en experiencias", siendo el factor innovación uno de los puntos más importantes (Benavides, 2013).

En el Perú la nueva generación de centros comerciales modernos comenzó en el año 1997 con la inauguración del Jockey Plaza Shopping Center, que inicia el desarrollo sostenido de los malls en Lima (Orrego, 2011) y cambia por completo las reglas del juego de los malls: las tiendas se alquilan y le pertenecen a un mismo dueño (León-Gambetta, 2016). El éxito del Jockey Plaza trajo consigo la creación de Larcomar en el año 1998, Plaza San Miguel (con el formato moderno), MegaPlaza (2002) en Lima Norte, que determinó que los habitantes de Lima Norte contaban con recursos suficientes para hacer viable este tipo de inversiones. Estos centros comerciales consolidaron la primera gran etapa del sector. La segunda inicia con la apuesta en las provincias (El Comercio, 2015).

Para Arellano (2013) la creación de un centro comercial con oferta moderna trae como primera ventaja la disminución de los costos de compra de los vecinos. Por lo que abrir un centro comercial en una zona periférica o en una provincia hace que las personas que antes se movilizaban largas distancias para encontrar los productos deseados, lo hagan de manera menos onerosa en transporte y tiempo. En segundo lugar, porque las estructuras comerciales crean empleos en las zonas donde se encuentran. En tercer lugar, porque se convierte en la zona de encuentro social de cuya falta adolecen muchas ciudades y zonas nuevas que crecieron de manera desordenada. Por último, porque su construcción genera un sentimiento de orgullo en la población aledaña, al ser símbolo de progreso y de modernidad.

Arellano Marketing (2012) en su investigación sobre centros comerciales 2012 muestra que el consumidor que compra o utiliza algún servicio de centros comerciales en Lima se encuentra en mayor medida en los rangos de edad de 18 a 25 años (32\%), seguido de 26 a35 años (29\%). En menor medida, se aprecia los rangos de edad de 36 a $45(21 \%)$ y 46 a $65(18 \%)$. En Lima Norte se aprecia el mismo principio, ya que el público que más compra o utiliza los centros comerciales se encuentra en los rangos de edad de 18 a 25 años (36\%), seguido del rango de edad de 26 a 35 (28\%), en menos proporción lo hacen los rangos de edad de 36 a 45 (19\%) y 46 a 65 (17\%). La misma 
empresa señala que los atributos más importantes que el público de Lima toma en cuenta para elegir un centro comercial son "que cuente con seguridad dentro y fuera del centro comercial", "que siempre haya ofertas", "que haya varias tiendas para comparar precios", "que tenga buenos precios/accesibles", "que sea un lugar para toda la familia", "que haya los restaurantes y lugares para comer que me gustan", "que haya entretenimiento para los niños", "que tenga un ambiente agradable y relajante", "que tenga todo en un solo lugar (variedad de marcas, productos y servicios", "que sea un lugar fácil de llegar, "que se pueda caminar cómodamente/no haya mucha gente".

El informe final de Arellano Marketing (2014) sobre centros comerciales indica que el Jockey Plaza, MegaPlaza y Plaza Norte son los centros comerciales más recordados en Lima. El Jockey Plaza y MegaPlaza cuentan con mayor valor percibido por los consumidores. Aclara que actualmente no existe una marca líder en el mercado.

\subsection{Centro Comercial MegaPlaza}

Pertenece al Grupo Wiese que junto a la Administradora Panamericana S.A.C ponen en marcha el proyecto MegaPlaza. Ubicado en el distrito de Independencia sobre Panamericana Norte. Fue el primer gran centro comercial súper-regional en establecerse en la zona Norte de Lima, operando desde el 2002.

De acuerdo a Regalado et al. (2009) las zonas de afluencia de MegaPlaza comprende los distritos de Carabayllo, Comas, Independencia, Los Olivos, San Martín de Porres, Rímac, Ventanilla, Cercado de Lima, Carmen de la Legua y el Callao.

Para el año 2009, en comparación con su competencia directa, los ambientes que MegaPlaza ofrece crean la sensación y provocan la percepción de un ambiente seguro para el consumidor (Regalado et al., 2009). Adicionalmente, Mayorga, Araujo y Schwalb (2004) añaden que otra competencia estuvo representada por los supermercados a los que asistía de forma masiva el grupo "tradicional" de Lima Norte. El supermercado constituía su paradigma de centro comercial. La presencia de los otros 
centros comerciales también representaba una competencia para MegaPlaza como el Jockey Plaza Shopping Center y Plaza San Miguel.

MegaPlaza en el año 2004 gana un Effie de Oro por "Mejores prácticas del marketing" en la categoría "lanzamiento de servicios" otorgado por la Universidad del Pacífico. El caso MegaPlaza como lo sugieren Mayorga, Araujo y Schwalb (2004) tiene como uno de sus factores de éxito la investigación realizada en los distritos de Lima Norte que revelaron los requerimientos de los residentes de la zona como:

- La menor distancia: el local para realizar las compras debía ubicarse en un lugar que no requiriera más de 30 minutos de viaje para llegar a él.

- El buen trato: el público se quejaba de que el trato en los centros comerciales existentes tendía a ser discriminatorio.

- La oferta acorde con las exigencias del cliente: la gente sentía que no existía una oferta de productos que fuera económica, de calidad y que considerara su estilo de vida; es decir, no existía una oferta hecha a su medida.

- El centro comercial «cercano»: el público buscaba que el centro comercial se convirtiera en un lugar al cual fuera posible asistir con su familia, amigos y conocidos; en donde se sintiera a gusto.

Mayorga, Araujo y Schwalb (2004) manifiestan que la empresa vio la oportunidad de incursionar en un nuevo mercado: Lima Norte, ya algunos supermercados se habían aventurado, con éxito, a abrir locales en esta zona. Además, la investigación realizada le permitía identificar los elementos que debía considerar para que su público objetivo se sintiera atraído a acudir al nuevo centro comercial. Se tomó en cuenta, que en Lima Norte existía un número aproximadamente 1.660.000 habitantes, que eran mayores de 18 años (61\% del total). Esta población contaba con un ingreso promedio mensual de 1.220 nuevos soles. La empresa también vio una oportunidad en el hecho de que no existiera un desarrollo comercial de la envergadura del MegaPlaza en la zona, y que era factible encontrar áreas adecuadas en tamaño y en ubicación para desarrollar este tipo de proyecto.

La empresa identificó cuatro grupos en que se dividía la población de Lima Norte en función a su estilo de vida. Los "tradicionales" y "aspiracionales" constituían su mercado potencial. Los "tradicionales" se caracterizaban por formar parte del grupo de 
migrantes cuyo patrón de estilo de vida y consumo era más conservador, con mayor asistencia al supermercado (paradigma de centro comercial para la zona). Los “aspiracionales" integraban el sector más moderno y tenían mayor conocimiento de la oferta; solían acudir a centros comerciales como Plaza San Miguel y Marina Park. En general, la población de Lima Norte se caracterizaba por acudir a diversos mercados como Gamarra y Polvos Azules y galerías como El Virrey, Surquillo y Jirón de la Unión (Mayorga, Araujo y Schwalb, 2004).

Arellano Marketing (2012) señala que el centro comercial MegaPlaza, en ese año, se encontraba en primer lugar de recordación - primera mención en su categoría. En el informe final sobre centros comerciales Arellano Marketing (2014) indica que MegaPlaza tiene el mayor nivel de recordación en primera mención (top of mind); así como asistencia y preferencia en Lima. Es el mall más recordado y visitado por personas de NSE C y D, principalmente por mujeres de estilo de vida moderna y conservadora. El principal sustituto de MegaPlaza es Plaza Norte y viceversa. MegaPlaza sería uno de los principales sustitutos de las personas que compran en Gamarra y Jirón de la Unión.

\subsection{Centro Comercial Plaza Norte}

Pertenece a la Corporación E. Wong. Ubicado en Lima Norte entre las avenidas Panamericana Norte, Tomas Valle y Túpac Amaru es un Centro Comercial súperregional. Inaugurado en el año 2009. Cuenta con $200,000 \mathrm{~m}^{2}$ de extensión por lo que es, hasta el momento, el mall más grande del Perú. Posee la mayor cantidad de espacios abiertos y áreas verdes. Su diseño sigue los conceptos del Feng Shui, así como las últimas tendencias mundiales en diseño, arquitectura y construcción (Petitjean, 2013). El área de afluencia que abarca son Comas, Carabayllo, Independencia, San Martín de Porres, Rímac, Lima, Los Olivos y San Juan de Lurigancho. 
El centro comercial Plaza Norte al pertenecer a la Corporación E. Wong, grupo que manejaba los supermercados Wong y Metro ha logrado trasladar la filosofía y cultura de sus supermercados a su mall, la misma que está orientada en la confianza, trabajo en equipo, creatividad (que se traduce en innovación constante) y vocación de servicio (Kato, 2013).

Hasta la fecha el centro comercial ha ganado tres premios. El primero, en el 2012 otorgado por la asociación de centros comerciales: International Council of Shopping (ICSC) el mismo que se entrega a los centros comerciales latinoamericanos. Plaza Norte ganó en la categoría de Diseño y Desarrollo Innovadores de un Proyecto Comercial Nuevo - 2012. Ese mismo año también ganó el premio Creatividad Empresarial 2012 otorgado por la Universidad Peruana de Ciencias Aplicadas (UPC) en la categoría de "Inmobiliaria Construcción y Equipamiento" por sus veinticinco conceptos ancla (Metro, Makro, Maestro, Centro Financiero, Expomotor, MAC conjunto de entidades del Espado en un solo lugar-, Expoinmobiliaria, Museo Chinen, gimnasio con piscina temperada, 2 institutos de idiomas, 5 tiendas departamentales, Boulevard de Restaurantes, Patio de Comida, parque de diversiones con $6,000 \mathrm{~m}^{2}$ de juegos para niños y adultos, más de 3,000 estacionamientos, 14 salas de cine, Gran Terminal Terrestre, Villa de Papa Noel, Teatro Plaza Norte, Capilla "Nuestra Señora de Loreto", eventos culturales y artísticos). En el 2013, ganó el premio Creatividad Empresarial en la categoría de Gastronomía por su Plaza Tradiciones, por desarrollar un food court no tradicional basado en la oferta de comida popular peruana.

En el estudio sobre centros comerciales del 2012 realizado por la casa investigadora Arellano Marketing señala que Plaza Norte, en ese entonces, se encontraba en sexto lugar de recordación en su categoría. Además, su nivel de preferencia lo localizaba también en el sexto lugar.

El informe final de Arellano Marketing (2014) indica que Plaza Norte se encuentra en la sexta mención de marcas de centros comerciales en Lima. Ocupa el tercer puesto en recordación de marca de centros comerciales en Lima antes se encuentra Jockey Plaza y MegaPlaza. Es más recordado y visitado por personas de NSE C y D, principalmente por mujeres de estilo de vida moderna y conservadora, el rango de edad que más asisten son de 18 a 25 seguido de 26 a 35 . El principal sustituto de Plaza Norte es MegaPlaza y viceversa. Otro sustituto sería el Real Plaza. 
El presente trabajo de investigación tiene como objetivo principal conocer la percepción e imagen actual que se forma entorno al Centro Comercial Plaza Norte, en el consumidor joven entre 18 a 35 años. Además, los objetivos específicos que se busca hallar son los siguientes:

- Analizar la identidad corporativa del Centro Comercial Plaza Norte

- Conocer las estrategias específicas que utiliza el Centro Comercial Plaza Norte para diferenciarse de su competencia desde el punto de vista de los ejecutivos

- Determinar la imagen que percibe el público joven entre 18 a 35 años sobre el Centro Comercial Plaza Norte

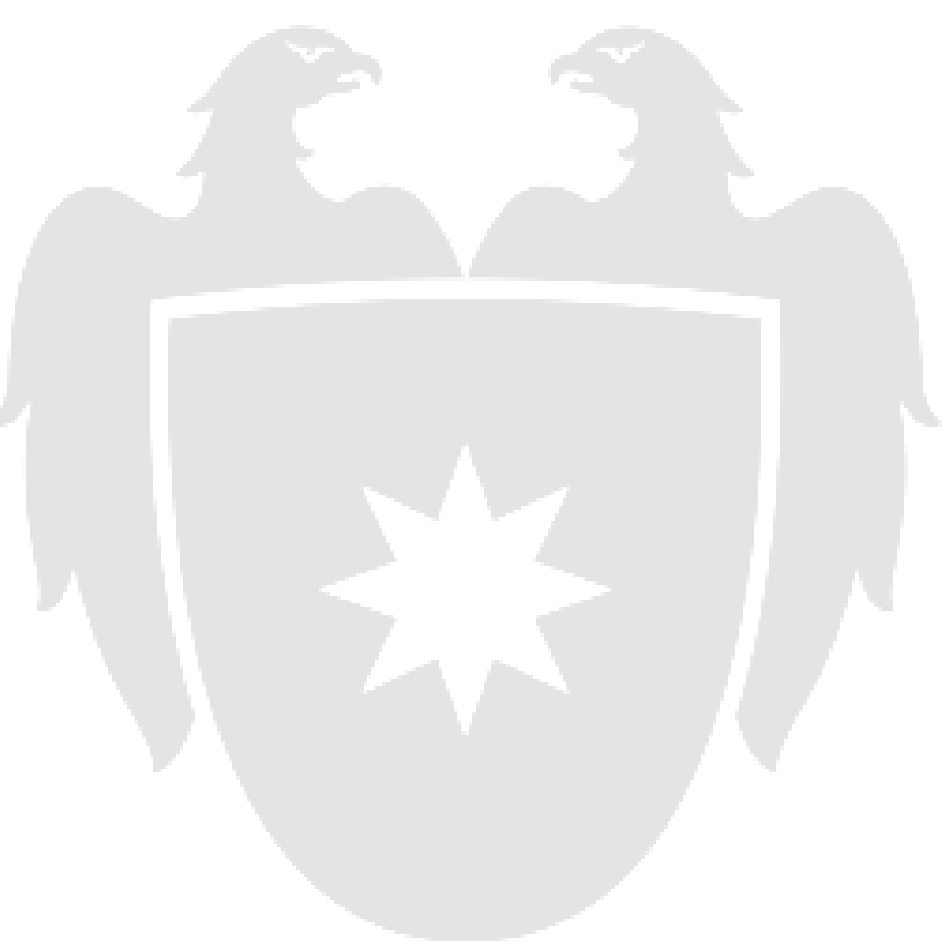




\section{CAPÍTULO II: METODOLOGÍA}

La propuesta metodológica de este trabajo de investigación se basó, en mayor medida, en el enfoque cualitativo. Las percepciones, imágenes y experiencias son aspectos intangibles que se forman en el interior del ser humano. Estas no se pueden medir fácilmente, muchas veces están en el inconsciente y es mediante ciertas técnicas que, lo que pensamos o vivimos, se revelan después de haberse planteado una reflexión. Por lo tanto, esta propuesta metodológica, permite conocer de manera más profunda al público investigado. En ese sentido, se utilizaron en este proyecto tanto entrevistas a profundidad como focus group.

Las entrevistas fueron planteadas para los ejecutivos de ambos centros comerciales. Se propuso conocer desde una mirada interna y más cercana la identidad corporativa que le querían asignar a sus respectivos malls, así como sus estrategias diferenciadoras.

En total se realizaron tres entrevistas con duración de alrededor 40 minutos y 1 hora y media. Los ejecutivos entrevistados de Plaza Norte fueron el Gerente de Centros Comerciales e Inmobiliaria de la Corporación E. Wong y el analista de Marketing de Plaza Norte. La ejecutiva entrevistada de MegaPlaza fue la jefa del área de marketing. En todas las entrevistas se abordaron los siguientes ejes temáticos: imagen que se quiere proyectar, estrategias utilizadas, visión acerca de la competencia y mirada del futuro del centro comercial.

Posteriormente para determinar y contrastar si la identidad que los ejecutivos deseaban brindar era realmente percibida. Se realizó 4 sesiones de grupos focales mixtos (tanto género femenino como masculino). Los ejes temáticos planteados fueron sobre los centros comerciales en general, comparación entre MegaPlaza y Plaza Norte, y preguntas exclusivamente acerca del centro comercial Plaza Norte. La cantidad fue 5 personas promedio en los focus group. El tiempo de cada reunión fue alrededor de 45 minutos promedio. La selección de las personas y ejecución de la sesión se llevó a cabo en el mismo centro comercial. Los requisitos para ser participante era tener entre 18 y 
35 años de edad, asistir al mall como mínimo 2 veces al mes. Además, haber visitado MegaPlaza.

En la segunda etapa, se utilizó el espacio cuantitativo para medir y corroborar lo antes descubierto en la etapa cualitativa. Se realizaron 110 encuestas presenciales en el mismo centro comercial Plaza Norte. Antes de entregar el cuestionario se preguntó la cantidad de veces que habían asistido al mall, siendo 1 vez al mes el mínimo requerido para pertenecer al target. De la misma manera, era necesario haber asistido a MegaPlaza, por lo menos, más de una vez. Esta técnica llevó cuatro días seguidos debido a que muchas personas se negaban a contestar por desconfianza.

Utilizar ambos espacios metodológicos tanto cualitativo como cuantitativo permitió obtener una visión más integral, completa y holística de la investigación. Por el lado cualitativo se consiguió profundidad y complejidad, mientras que por el cuantitativo magnitud. 


\section{CAPÍTULO III: RESULTADOS}

\subsection{Identidad Corporativa}

\subsubsection{MegaPlaza}

La ejecutiva del centro comercial MegaPlaza en la entrevista realizada señala que los valores a nivel cliente interno que desean transmitir están basados en "la comunicación, honestidad, trabajo en equipo, responsabilidad". A nivel cliente externo sus pilares están orientados en "ser los mejores, líderes y pioneros siempre en la zona de influencia” así como ser el eje comercial de Lima Norte.

El público principal al que se enfoca provienen de los distritos de Los Olivos, Comas, Independencia y San Martín de Porres al que considera progresista, moderno y aspiracional, citando a Arellano. Su target principal son las familias.

Una de sus fortalezas que observa es que llegaron primeros: son los pioneros, al haber ofrecido una oferta comercial en Lima Norte. Otra fortaleza que remarca, es que cuentan con más áreas arrendables que su competencia Plaza Norte, al que considera su única competencia directa.

Resalta, la ejecutiva, que MegaPlaza es el centro comercial más visitado a nivel nacional; además, de ser el preferido a nivel nacional, citando un estudio de Arellano emitido en el 2012. Su visión se centra en seguir innovando y continuar siendo los líderes.

\subsubsection{Plaza Norte}

Tanto el analista de marketing de Plaza Norte como el Gerente de Centros Comerciales de la Corporación E. Wong en las entrevistas realizadas señalan que la identidad de su centro comercial está fuertemente marcada por la cultura Wong la que 
se trasladó a su centro comercial: "hemos mantenido la estructura cultural y valores de Wong”. La estructura de valores está formada por cuatro pilares. Primero: el cliente es la razón de ser, orientándose a satisfacer al cliente brindándoles servicio superior al nivel promedio, que señalan es la clave de su éxito. Segundo: preocupación por el colaborador, que se sienta satisfecho, motivado, bien tratado y convencido de su labor, así estará dispuesto a ayudar al cliente. Tercero: innovación, pensar en hacer mejor las cosas para que el cliente goce una mejor experiencia o un mejor servicio. Cuarto: desempeño superior, preocupación porque el colaborador alcance niveles de desarrollo personal y profesional del más alto nivel.

Siguiendo la misma línea del desempeño superior tienen como misión "ser líderes con nivel de competencia mundial", "así ha sido desde Wong. Fuera de la institución hemos sido reconocidos a nivel mundial por el nivel de servicios; en el centro comercial se mantiene la misma estructura". Agregan que, por ser una empresa familiar, "su cultura es de clan, de familia. Existe gran confianza en el personal y son tratados como familia".

Subrayaron que el Grupo Wong previamente tuvo experiencias en retail, ya que desarrollaron Power Centers en varias locaciones con tiendas anclas como Wong y Metro. Esta experiencia los llevó a lanzar Plaza Lima Sur (que fue transferida a Cencosud) y, posteriormente, incursionar con Plaza Norte en Lima Norte.

Su interés es ser la Plaza Mayor de Lima Norte "esa Plaza Mayor que hace que la gente los domingos se arregle para encontrarse, sean jóvenes, mayores o niños. Van, juegan, se distraen y se quedan ahí. Es su plaza, la quieren, se identifican con ella y es parte de su identidad". Por ello, los elementos creados se basan en lo que existe en una Plaza Mayor.

"Deseamos que se nos visualice como un centro comercial muy limpio, moderno, ordenado, iluminado, tecnológico, surtido, variado, agradable, que no sea una plaza pública más. En horas picos que esa sensación agradable no se pierda". "Ser un mall donde la gente esté dispuesta a servir, a atender, a ser orientada. Un mall donde te encuentres con servicios diferentes". "El valor diferencial sea apreciado en los productos innovadores que se ofrece y que no encuentran en otro centro comercial".

Se señalizó que existe una preocupación en temas sociales y culturales. Por este motivo ofrecen opciones al público para que disfruten de mejores servicios, un ejemplo 
es el terminal terrestre. Este elemento hace que el público se acostumbre a la formalidad, que viajen en un lugar seguro, en una empresa formal y puntual. Otros elementos son los eventos culturales y artísticos que realizan.

El público objetivo es A, B enfocándose en la familia; sin embargo, "hay bastante acogida del público joven".

\subsection{Estrategias Diferenciadoras}

\subsubsection{MegaPlaza}

La ejecutiva señala que su estrategia principal se basa en la innovación constante: infraestructura, campañas, temas operativos, proyectos, acciones, entre otros.

Las estrategias que proponen se basa en actividades con sorpresas y premios cada día para que "el cliente viva una experiencia en la que siempre será sorprendido". Las acciones que suelen plantear duran entre 1 a 3 meses. "Nuestra última acción fue un concurso, una exhibición de las esculturas que duró alrededor de 6 meses; sin embargo, las acciones no suelen pasar de 3 meses".

Cuentan con canal de ventas online Ofertop "donde el cliente compra online, pero recoge el producto en el mall. "El objetivo es que cuenten con algún súper descuento". Las redes sociales son consideradas dentro de sus estrategias, lo plantean como una interacción con sus clientes y además para generar engagement. Por ello cuentan con página web, Twitter, Instagram, Facebook, YouTube y Foursquare. La ejecutiva considera que las redes le permiten escuchar qué es lo que desea su público y en base a eso actuar.

Otra estrategia que plantean, pero temporal es que algunos fines de semana existan promociones o outlets, en los que las prendas se encuentran con grandes descuentos. 
Al ser su target principal las familias sus actividades, acciones, campañas se dirigen a ellos, para que pasen de dos horas a más en el mall compartiendo tiempo con sus seres queridos. "Por eso el acuario, ya que atrae a la familia: al niño, al abuelo, al tío, al papá". Han creado un club de niños "para fidelizar a la familia: a la mamá y al niño, desde pequeño hasta grande".

\subsubsection{Plaza Norte}

Las estrategias que se desprenden de uno de sus valores como empresa: el cliente es la razón de ser, se basa en ofrecer lo mejor al cliente. Este principio se aprecia tanto en el cuidado de la infraestructura: piso, materiales de construcción, espacios entre corredores, baños bien cuidados y en el servicio: buen trato al cliente.

Otro de sus valores se basa en innovación que se observa en conceptos como Plaza Tradiciones (concepto de patio de comidas popular con mesas, sombrillas, calefacción, música en vivo y luces), La Granjita (espacio para que los niños interactúen con animales domésticos), Villa de Papa Noel, Gran Terminal Terrestre". En la misma línea de innovación, los ejecutivos comentan que cuentan con pantallas digitales grandes dentro del mall.

Sus estrategias centradas en ser una Plaza para Lima Norte consisten en tener $3,000 \mathrm{~m}^{2}$ cuadrados de áreas verdes, contar con jardines, parques, piletas, plazas, paseos, bulevares para que "la gente no solo asista a comprar sino a pasear con la familia, para que se relaje". Además, cuentan con servicios financieros, bancarios y públicos. Por lo que ofrecen el MAC, ONP, Banco de la Nación.

Por otro lado, las estrategias centradas en temas sociales y culturales se sustentan en el Museo Chinen, Museo Caral, La vuelta al mundo en 8 minutos, Sala de Lactancia, Capilla. Así como el Show del Dragum. "Estas son cosas que no generan utilidad, porque no se cobra por entrar ahí, pero cubren la necesidad del público". A estos conceptos se le suma el Teatro Plaza Norte, las exhibiciones como Dinosaurios Gigantes Animatronics. También, conciertos, festivales de marinera, Día del Ceviche, entre otros eventos tanto culturales como artísticos. 
Otras estrategias aparte de los veinticinco conceptos ancla son el uso del perfume para generar una sensación de bienestar. Además, "estar atento a todos los detalles para que el público goce de una experiencia memorable". "En general las estrategias están centradas para que el cliente se identifique, tenga más fidelidad y más razones para ir al centro comercial, no las típicas razones de solo comprar”.

Utilizan tanto los medios tradicionales como los digitales para dar a conocer sus productos y servicios. En medios tradicionales utilizan pautas televisivas durante casi todo el año en los canales de televisión América y ATV. En periódicos: Trome. En cuanto a medios digitales, utilizan redes sociales como Facebook, Twitter, YouTube, Google+ e Instagram. Son auspiciadores de eventos como la Copa Unique 2013, el Mundial FIFA Brasil 2014. Auspician también equipos como Universitario de Deportes; más adelante piensan ser, a la vez, sponsor del equipo Alianza Lima.

Realizan promociones permanentes en las que el cliente esté sujeto a compras dentro del centro comercial, premios como autos, camionetas, viajes en familia todo pagado. "Los localizamos por medio de Facebook y la base de datos que manejamos. Siempre estamos en contacto con nuestros clientes". Adicionalmente, promueven la acumulación de los Puntos Bonus dentro del centro comercial.

\subsection{Imagen Percibida}

\subsubsection{Mega Plaza}

El público participante del grupo focal consideró que el ingreso a MegaPlaza es fácil, porque cuenta con un puente que conecta directamente con el mall "en Plaza Norte se tiene que cruzar la pista que no es muy segura y no cuentan con un acceso directo como en MegaPlaza”. Además, consideraron que las otras puertas de entrada de MegaPlaza son fáciles también para ingresar, debido a que no se demoran al momento de cruzar hacia el centro comercial. Sin embargo, comentaron que el tránsito en cuanto a acumulación de carros es complicado y les genera malestar. 
Valoraron la oferta de tiendas especializadas y de renombre internacional como las que están abiertas al público en Plaza Conquistadores. En la misma línea, les agradó que constantemente se encuentren ampliando nuevas zonas para contar con más tiendas. Otro aspecto que consideraron importante es el escenario que tienen, el que se encuentra rodeando el patio de comidas "te puedes sentar y escuchar música o ver los eventos que hay".

Consideraron que en cuanto a espacio MegaPlaza es mucho más grande o, por lo menos, eso les parece cuando se encuentran caminando dentro del mall. Sin embargo, mencionaron que si bien es grande no se sienten a gusto caminando por la cantidad de gente que asiste, lo que les genera, a la vez, inseguridad. "Es casi imposible caminar por el cúmulo de gente, te chocas constantemente con alguien, es imposible estar tranquilo, las colas son inmensas. Hay bastante gente y te pueden meter la mano al bolsillo". Agregaron que lo observan desordenado.

Aseguraron que cuando van a MegaPlaza es más que nada para comprar algún producto, no tanto para pasar el tiempo. "Es más para hacer shopping".

Mencionaron que MegaPlaza los remitía a su infancia, porque fue el primer centro comercial en llegar a Lima Norte; además, les brindaba mayor cercanía. "Recuerdo nuestra infancia, en Los Olivos hace 8 años solo había MegaPlaza. Era el centro comercial que estaba más cerca”.

El público estuvo de acuerdo que el segmento al que va dirigido el centro comercial MegaPlaza es mayormente a familias y al niño. "Existen shows infantiles, talleres y un club para ellos". Señalaron que si fuera una persona está sería una mujer madre de familia mayor a 30 años, medio "llenita" y que se enfoca en su familia".

Las palabras que asociaron con MegaPlaza cuando se les preguntó qué es lo primero que se les viene a la mente o recuerdan fue "tiendas, Coney Park, KFC, Saga Falabella, shows infantiles". A la vez, mencionaron palabras como "desorden, antiguo, tráfico, congestión, mucha gente, saturados, estresados”.

En las encuestas realizadas en la pregunta 14 se utilizó Diferencial Semántico para medir adjetivos relacionados a MegaPlaza, adjetivos que fueron extraídos previamente de los grupos focales. El público participante consideró para los siguientes 
adjetivos que el centro comercial MegaPlaza no es ni conservador ni innovador, ni lento ni ágil, ni antiguo ni moderno, ni barato ni caro, ni desinteresado ni ambicioso; es decir que lo centraron en un punto medio neutral. Para el par de antónimos sucio-limpio, coincidieron en que es limpio. Se observa, un movimiento hacia el adjetivo positivo. En los pares de antónimos viejo-joven y oscuro-luminoso señalaron que lo ven bastante joven y bastante luminoso.

\subsubsection{Plaza Norte}

El público que participó en el grupo focal consideró que existe un problema en el acceso al ingresar a Plaza Norte; además, que no cuenta con semáforos ni con un puente peatonal. Cuentan con varias puertas de ingreso, pero remarcaron que es difícil ingresar por la entrada de la Panamericana Norte. Las puertas de Tomas Valle y Túpac Amaru no les presentó ningún inconveniente. "El problema en cruzar es la Panamericana Norte. Ese es el problema, porque no hay semáforos ni puente, si ves un carro no sabes si cruzar o no. Es a la de Dios. Es un reto". Adicionalmente, consideraron que el Gran Terminal Terrestre complica el tráfico de la zona.

Valoraron de Plaza Norte su modernidad, preocupación por los detalles e innovación permanente. "Es bastante moderno, tiene dos ascensores. Tratan de resaltar la belleza del centro comercial, más allá del aspecto comercial". "Tienen un mejor ambiente, constantemente están creando nuevos ambientes. Cada vez que regreso quiero ver qué hay de nuevo. Ahora ya tienen luces de colores que antes no había. Tiene menos años y está innovando más que MegaPlaza”. Perciben mayor comodidad y amplitud en los espacios "es más amplio y cuentan con más lugares para caminar, MegaPlaza es todo cerrado, rodeado de tiendas". Agregaron que existe mayor seguridad. "Cuando veo a los hombrecitos de chalequito amarillo me siento segura y siento confianza". "Hay seguridad permanente en todos lados del centro comercial".

Consideraron que es un mall que se encuentra en crecimiento continuo y planificado. "Ha ido creciendo y creciendo, eso es importante en un centro comercial". Ha crecido de manera planificada, "se ve en el orden. En el segundo piso están los 
niños, en el primero es más para mujer”. Señalaron que existe una mayor cantidad de servicios que ofrece para agilizar los trámites. "Se pueden hacer trámites". La variedad de tiendas fue un elemento que también mencionaron.

El público participante comentó que cuando asiste a este centro comercial realizan actividades como ir de compras, ver tiendas, hacer trámites, comer, ir al cine y pasear y pasar el tiempo. "Cuando estoy solo camino, pero si estoy con mi familia vamos al cine, a comer o a comprar". "A veces solo vengo a pasear con mis amigos". "Lo bueno es que puedes pasear tranquilo, sin que estés tocándote con todo el mundo". Cuando asisten usualmente lo hacen con algún acompañante sea este familiar, amigo o pareja. Comentaron que el tiempo que se quedarían en el centro comercial si es posible todo el día. "Las 24 horas, porque hay de todo un poco".

Comentaron que cuando se encuentran dentro del centro comercial este les genera sentimientos como tranquilidad, seguridad, relajo, distracción y comodidad. "Me distraigo cuando estoy acá. Es más entretenido". "Me siento relajada. Solo pienso en distraerme". Agregaron que se sienten seguros, mucho más que en MegaPlaza. "En estos tiempos, lo mejor que te pueden hacer sentir es seguro y aquí yo me siento hasta un 90\% seguro. Acá difícilmente te roban”. "En MegaPlaza el tumulto de personas hace que te sientas inseguro, puedes estar caminando y te 'meten' la mano al bolsillo".

Dentro de sus conversaciones hablan del centro comercial con sus amigos y familias, sobre todo, si ven alguna novedad, si abren tiendas nuevas o existen promociones. "Hablamos sobre las nuevas tiendas o lo que están haciendo, incluso hacemos planes para ir cuando lo inauguren". "Planeamos ir fechas como el día del shopping o cuando hay La Villa de Papa Noel. Siempre que hay novedades". "Yo les digo me compre tal cosa o les comento que es lo que hice".

Utilizan las redes sociales para compartir momentos dentro del centro comercial Plaza Norte haciendo check in del lugar. "Cuando me tomo foto en los paneles grandes que tiene diferentes lugares lo subo a mi Facebook, porque esas fotos parecen reales". Sin embargo, comentaron que si bien siguen la página oficial del Facebook de Plaza Norte y le han otorgado like interactúan poco con la misma, poniéndole, de vez en cuando, me gusta a sus publicaciones. "Yo lo veo, pero no comento. Solo veo las fotos y le doy like". 
Suelen enterarse de las novedades de Plaza Norte por redes sociales, o cuando se encuentran dentro del mismo centro comercial, por televisión, por la página web o por correo que el mismo mall les envía. "Lo veo cuando pasan en el canal ATV y cuando se hablaba del mundial". "Veo lo que hacen por su Facebook".

Las palabras que asociaron a Plaza Norte cuando se les preguntó qué es lo primero que se les viene a la mente cuando piensan en este centro comercial son “espacioso, innovación, sorpresas, orden, seguridad". Al preguntarles por una emoción que relacionarían con el centro comercial el público respondió "tranquilidad, serenidad", porque "alivia varias cosas, se tiene todo a la mano. Es completo". "Existen espacios para relajarte". Para el público participante este mall significa "confianza y seguridad".

Al preguntarles sobre las cosas que le parecen únicas del centro comercial mencionaron en mayor medida el terminal terrestre y teatro; en menor medida, su capilla y Villa de Papa Noel. "Lo más rescatable de Plaza Norte es su terminal terrestre". Adicionalmente, señalaron elementos como sillas y piletas.

Las experiencias que el centro comercial les ha brindado han sido, sobre todo, de recreación. Indicaron que comprenden que los centros comerciales son también para pasar el tiempo y no solo comprar "aquí hay esculturas, tableros de ajedrez gigantes, no solo es comprar". Igualmente comentaron que les sorprendió cuando anunciaron que inaugurarían el teatro o la presentación de diferentes eventos culturales. "Cuando lo vi dije: ¡un teatro en el Cono Norte! Eso es lo bueno". "Ver espectáculos".

En el supuesto de que el centro comercial les obsequiara un regalo con el logo del mismo, los participantes respondieron que sí lo utilizarían, sobre todo, si el signo es pequeño. "Si, normal”. "Sí lo utilizaría, sí me siento identificada". En el caso de que Plaza Norte dejara de operar en Lima Norte el público sentiría tristeza. "Tristeza, porque no habría otro lugar así para visitar". "Me daría pena, porque me tendría que ir a MegaPlaza, otra vez". Al preguntarles en qué centro comercial, de los que visitan frecuentemente, se sienten más a gusto, la mayoría respondió Plaza Norte, remarcaron que lo prefieren por los espacios y la sensación de seguridad y tranquilidad que perciben.

Consideraron que el público al que va dirigido es gente joven, porque es "moderno, tiene discoteca, bares y una mayor oferta para los jóvenes". Si fuera una 
persona sería una mujer de alrededor 25 y 28 años, ordenada, ejecutiva, entusiasta, detallista, le gusta ver películas, siempre quiere destacar, viaja y siempre va a la moda.

En la aplicación del cuestionario en la pregunta 7, ¿qué servicios recuerda, en estos momentos de Plaza Norte? Más del $40 \%$ del público contestó: "tiendas", haciendo referencia a las tiendas especializadas y tiendas por departamentos. Un $30 \%$ respondió: “comidas" haciendo alusión tanto a patio de comidas como restaurantes. Un $20 \%$ señaló algún concepto ancla del centro comercial como el Gran Terminal Terrestre, teatro, MAC o Expomotor. El 7\% manifestó palabras asociadas a limpieza, tranquilidad, buena atención. El 3\% restante recordó elementos como sillas, piletas y bancas.

$\mathrm{Al}$ preguntarles sobre ¿qué considera único de Plaza Norte, que no haya visto en otro centro comercial? Un $30 \%$ señaló tiendas especializas. $20 \%$ mencionó terminal terrestre y teatro. Otro $20 \%$ hizo referencia a lugares de entretenimiento pagado como Cinépolis, discotecas, bares. El otro $20 \%$ hizo referencia a elementos como bancas, piletas y amplitud de espacios. El 10\% restante señaló algún concepto ancla como el museo, Villa de Papa Noel, ajedrez gigante, aurora boreal, fotografías gigantes.

En la pregunta acerca de qué servicios conoce o recuerda haber visto se les presentó una lista con los elementos más resaltante y que forman parte de los 25 conceptos ancla (Ver anexo 8). Los resultados más resaltantes que el público respondió fueron Teatro Plaza Norte con más del 50\%, Expomotor con 44\%. Y Banco de la Nación con 40\%. En el apartado "Otro (especifique)" el 3\% escribieron terminal terrestre.

Dentro de los elementos que valora de Plaza Norte indicaron variedad de tiendas (74\%), variedad de servicios (44\%), limpieza (43\%), amplitud de espacios (39\%), puntos de encuentro (36\%), orden (33\%) y otro (2\%). (Ver anexo 9).

A la pregunta en "Plaza Norte me siento..." más del 50\% respondió entretenido, seguido de $47 \%$, que contestó relajado. El 44\% indicó seguro. En menor medida el público mencionó confortable (28\%), alegre (17\%), sorprendido (10\%), estresado $(5 \%)$ y aburrido $(3 \%)$.

El ingreso al centro comercial Plaza Norte es considerado fácil con más del $70 \%$. Menos del 30\% restante lo consideró difícil. 
En el Diferencial Semántico utilizado en la pregunta 13, los participantes consideraron que el centro comercial Plaza Norte no es ni barato ni caro, centrando este par de adjetivos en un punto medio: neutro. Para el par de antónimos desinteresadoambicioso tiende a ser ambicioso. Para los adjetivos restantes los encuestados opinaron que el centro comercial es bastante innovador, joven, ágil, moderno y limpio. Adjetivos que son positivos.

A la pregunta si Plaza Norte dejara de operar en Lima Norte, más del 65\% del público encuestado señaló que se sentiría triste. El 33\% respondió que le da igual y menos del $1 \%$ contestó contento. 


\section{CAPÍTULO IV: DISCUSIÓN}

\subsection{Identidad Corporativa}

\subsubsection{MegaPlaza}

Los valores que MegaPlaza promueve a nivel interno se basan en la comunicación, honestidad, trabajo en equipo y responsabilidad. Mientras que de cara al público se centran en ser los líderes y pioneros en su zona de influencia. De acuerdo a las investigaciones realizadas por Arellano Marketing sobre centros comerciales en los años 2010 y 2012 demuestran que MegaPlaza es el centro comercial que goza de mayor recordación, asistencia y preferencia en Lima. Lo cual lo hace coincidir con la perspectiva de "ser primeros" que sus ejecutivos le confieren.

El público, que fue parte de la investigación realizada, responde positivamente ante este último valor y recuerda que MegaPlaza fue la primera gran oferta comercial moderna en llegar a la zona de Lima Norte. Lo que les genera cariño. Cabe recordar que, como se ha mencionado en la literatura precedente, MegaPlaza fue el primer centro comercial súper-regional en establecerse en la zona y demostrarle al público cómo es un mall moderno: gran extensión, diferentes tipos de servicios, tiendas conectadas por pasillos, estacionamiento amplio y tiendas anclas.

Antes de existir MegaPlaza, la población de Lima Norte asistía a establecimientos como Gamarra, Polvos Azules y Jirón de la Unión, entre otros, para realizar sus compras. Sin embargo, estas opciones no ofrecían cercanía, la posibilidad de ir con la familia y sentirse seguros, una oferta de productos hecha a su medida, ni buen trato. El otro grupo (público moderno y aspiracional de Lima Norte), asistía a comprar y pasear a Plaza San Miguel y Marina Park; sin embargo, trasladarse hasta estos lugares les demandaba tiempo y dinero. El proyecto MegaPlaza fue la solución e integró a estos grupos que necesitaban una oferta acorde a sus necesidades. Es por eso que este centro comercial es recordado por el público con aprecio. Además, mantienen 
en su memoria, como lo desean sus ejecutivos, que fue el pionero en ofrecer una mejor oferta en la zona. Se convirtió en el símbolo que demostraba el progreso y modernidad de Lima Norte. Fue el primero en ofrecerle "un espacio para distraerse, estar con la familia y seguros”. Existe ese espacio de gratitud hacia MegaPlaza por permitirle al poblador de Lima Norte ser parte de un retail moderno. Esa gratitud y cariño que el público investigado no olvida.

Otra de las fortalezas que han mencionado es que cuentan con mayor área arrendable que su competencia directa Plaza Norte; sin embargo, como sugiere Benavides (2013), aspectos tangibles como infraestructura, capacidad del tenant mix, estacionamiento y facilidad de acceso pueden ser copiados por la competencia. Este tipo de elementos tangible solo genera compras impulsivas a corto plazo y no una a largo plazo que dirija a la fidelidad del consumidor.

Parte de la identidad del centro comercial es que está dirigido a las familias llegando al niño, a los padres y a los abuelos. En este sentido desean enfocarse desde que su público es pequeño para conseguir fidelidad cuando sean grandes. De esta manera estarían presentes en la vida de su target, desde que este es pequeño hasta que se convierte en adulto mayor, creciendo y pasando todas sus etapas junto a ellos.

La visión que tienen es continuar siendo líderes y seguir innovando en infraestructura, campañas, temas operativos, etc. En cuanto se refiere a innovación en infraestructura el público lo aprecia claramente, ya que mencionan que MegaPlaza constantemente está construyendo nuevas áreas para ofrecer mayor cantidad de ofertas. La última gran construcción que el público parte de la investigación recuerda fue la Plaza Conquistadores que, a la vez, les ha generado aprobación y asistencia, ya que es la zona de las marcas internacionales.

\subsubsection{Plaza Norte}

La identidad del centro comercial Plaza Norte está fuertemente marcada por la cultura Wong. En este sentido mantienen la cultura de valores fundamentadas en cuatro pilares: el cliente es la razón de ser, preocupación por el colaborador, innovación y 
desempeño superior. De estos cuatro principios los percibidos por el público analizado son "el cliente es la razón de ser" e "innovación”. El cliente como razón de ser se observa con el trato y ambiente que se les ofrece, ya que en las instalaciones de este mall el público se siente en tranquilidad y bien tratado. Innovación, debido a que señalan que constantemente crean elementos nuevos que los sorprenden cuando asisten a este centro comercial. Les genera expectativa saber que otro componente nuevo puede existir la próxima vez que vayan sea este un nuevo punto de encuentro, luces, sillones, piletas que han sido los elementos más mencionados en el estudio.

De los cuatro pilares, los dos relacionados directamente al público han sido rápidamente captados por el público investigado. Para los principios de "preocupación por los colaboradores" y de "desempeño superior" que están dirigidos hacia el público interno, señalan que el ambiente creado para ellos es de clan, de familia.

Formar parte de la cultura Wong también implica recordar los ancestros chinos de este grupo empresarial, este elemento cultural es inherente a Plaza Norte. Se aprecia en la construcción del centro comercial basados en los lineamientos del Feng Shui, el diseño del mall que tiene la silueta de un dragón y los frecuentes shows del Dragum que recorre los pasillos de este centro comercial. Estos elementos que forman parte de la identidad de Plaza Norte no han sido captados por el público investigado, ya que no saben a qué grupo empresarial pertenece el centro comercial, no saben de las influencias de la cultura china y por ende no comprenden la relación de por qué dentro del mall existe un show llamado Dragum que cuenta la historia de un dragón chinoperuano que se enamora del ave Fénix. Tanto el grupo empresarial al que pertenecen como las tradiciones chinas son parte de la identidad de Plaza Norte que no ha sido captados y que tampoco ha sido parte de la preocupación de sus ejecutivos difundir; sin embargo, al ser parte de su identidad es importante comunicarlo.

Plaza Norte al pertenecer a un grupo poderoso económicamente en el Perú, tuvo la oportunidad de experimentar previamente en el mundo del retail; así también lo hicieron en Lima Norte donde contaban con Power Centers con tiendas anclas como Wong y Metro. Estas experiencias les permitió tener conocimientos del comportamiento previo del cliente de Lima Norte, saber sus gustos, preferencias, sus tradiciones, etc., que luego utilizaron para crear Plaza Norte. Por eso su enfoque sociocultural ha sido aceptado y captado por el público del estudio. Este planteamiento crea en el asistente sentimientos de pertenencia e identificación, pues les brinda los elementos "hechos a su medida" que antes de la creación incluso de MegaPlaza estaban 
buscando. Ser parte de shows como el Dragum, contar con un espacio donde se come comida popular o las clásicas comidas de carretilla, pero con salubridad, comodidad y seguridad y demás elementos que un centro comercial ofrece ha generado en el público aprobación e identificación.

El interés que Plaza Norte demuestra en constituirse en la Plaza Mayor de Lima Norte, como lo sugieren sus ejecutivos, ha sido bien recibido por el público parte de la investigación. Señalan que este centro comercial les brinda opciones de entretenimiento, poder pasear sin necesidad de comprar dentro del mall, sino solo caminar. Sirve también como punto de encuentro para los amigos y parejas. Esta afirmación está claramente sustentada en las palabras de los participantes de los focus groups "a veces, solo vengo a pasear con mis amigos". "Aquí hay esculturas, tableros de ajedrez gigantes, no solo es comprar". "MegaPlaza es más shopping". Estas expresiones sugieren que Plaza Norte está siendo reconocida como un lugar para el encuentro, entretenimiento, un lugar donde no necesariamente necesitas gastar dinero para divertirte.

El público al que va dirigido Plaza Norte está centrado en las familias; sin embargo, el público considera que está dirigido a un público joven por la cantidad espacios de entretenimiento y aspecto de moderno que visualizan.

\subsection{Estrategias Diferenciadoras}

\subsubsection{MegaPlaza}

A nivel general se sostiene que MegaPlaza tiene como principal estrategia la innovación en todo sentido: infraestructura, campañas, temas operativos, proyectos, acciones; sin embargo, lo único que el público percibe en cuanto a innovación es la ampliación de sus espacios.

En cuanto a lo que se refiere a las estrategias para fidelizar a su público estas se centran en estrategias promocionales del retail como las promociones, descuentos, outlets, actividades que implican sorpresa y premios. Por este motivo, el público 
investigado señala que MegaPlaza es más que nada un espacio que ofrece variedad para hacer compras "shopping".

El espacio online está siendo aprovechado para generar presencia. Además, de utilizarlo como un medio de interacción más cercano y humano con su público. Con esta herramienta pueden obtener un feedback directo de su público.

Las estrategias que mejor han sido captadas por el público objeto de la investigación es la referida al target de MegaPlaza: familias. El centro comercial ha creado el club del niño, que es bastante recordado por los participantes; cuenta con espacios grandes de diversión para niños; posee un acuario, que atrae para pasar un momento o tomarse fotos en familia. Existe en este punto cohesión y coherencia entre lo que MegaPlaza emite como mensaje y lo que el público percibe como imagen. MegaPlaza es familia. Sin embargo, es familia solo en su segundo piso (en el espacio donde niños, padres y abuelos llevan al niño a que se divierta) y en un tiempo acortado, ya que el público coincide que MegaPlaza no es un buen lugar para quedarse mucho tiempo, no es tanto para pasear por la cantidad de personas que asisten a este centro comercial.

\subsection{2. $\quad$ Plaza Norte}

Plaza Norte está utilizando diferentes estrategias para diferenciarse de su competencia, pero todas ellas tienen la misma característica: innovación. La innovación que está aplicando se aprecia en diferentes conceptos. Uno de ellos son sus veinticinco conceptos ancla. Lo más inusual que se puede observar es que cuentan con un terminal terrestre, una capilla y eventos culturales.

La innovación que utiliza Plaza Norte, de acuerdo a la literatura revisada anteriormente, es del tipo innovación incremental: mejoran o modifican algo ya existente. Los conceptos de terminal terrestre, capilla y eventos culturales han existido antes de ser creado Plaza Norte; sin embargo, no ha sido parte de la oferta de un centro comercial. Ahí se encuentra la innovación, sacar de su contexto habitual estos servicios y llevarlos a ser parte de un espacio que antes solo era percibido como un lugar de compras. 
De esta manera varios de los conceptos creativos de este centro comercial encajan en el tipo de innovación incremental, otros que siguen esta línea son Plaza Tradiciones (comida popular ofrecida en un centro comercial), Villa de Papa Noel, La Granjita y el teatro.

Las estrategias centradas en ser una Plaza para Lima Norte, para que la gente no solo asista a comprar sino también a realizar otro tipo de actividades, guarda relación con la infraestructura del centro comercial que cuenta con espacios de aireación o espacios libres con elementos de una plaza como son sus áreas verdes, piletas, luces, sonidos y sillas. Estos elementos presentes han servido de punto de encuentro para el público investigado. Ser una la Plaza Mayor en la que se quieren convertir ha sido planeado desde antes de la construcción de Plaza Norte, por lo que es un factor tangible que ha sido captado por el público investigado quienes además concluyen que estos espacios les genera sensación de tranquilidad. Son estos tipos de ambientes que vuelven su experiencia memorable, en este sentido, se está pasando de ser solo un tangible a ser un intangible, aquel que te genera una experiencia memorable.

Plaza Norte está afectando positivamente al público objeto de la investigación mediante sus cinco sentidos: vista, olfato, oído y gusto. Mediante la vista porque observan en este centro comercial ambientes diferentes y nuevos debido a la innovación que manejan, entre ellos se encuentran una gran cantidad de fotografías de diferentes partes del mundo a lo que han llamado "La Vuelta al Mundo en 8 Minutos". Olfato, por el perfume característico que se siente en las puertas del centro comercial. Tacto, debido a que existen ambientes con detalles diferentes que pueden ser palpados por el público como sus boulevares que tienen decoraciones que pueden ser tocados o las piletas con las que generalmente los niños interactúan mojándose. Oído, por la música que emana de la pileta principal que está sincronizada con la caída del agua. Por último, el gusto, ya que parte de la identidad de Plaza Norte es Plaza Tradiciones, este lugar donde los pobladores comen platos populares.

Las estrategias centradas en temas sociales y culturales de lo que forma parte los Museos Chinen y Caral, Shows del Dragum, comparsa, festivales, exhibiciones, teatro han sido captados en menor medida por el público quienes ven estas estrategias como parte de la oferta de entretenimiento que ofrece el centro comercial. El teatro es el mayor símbolo que ha sido asociado a cultura y por el que mayor cantidad de investigados se sintieron sorprendidos y a gusto de que exista en Lima Norte. 
Plaza Norte también muestra estrategias que han sido muy tomadas en cuenta en el retail de centros comerciales. Utiliza medios tradicionales como prensa, televisión y radio. Espacios que no han sido muy usados por otros centros comerciales para publicitarse, lo usual. Sin embargo, Plaza Norte tiene pautas seguidas en canales como América y ATV. Además, de promociones en el diario Trome. Las pautas televisivas les ha generado visibilidad ante el público investigado quienes comentaron que han visto los comerciales del centro comercial en señal abierta. Son auspiciadores de eventos relacionados al deporte como vóley y futbol. Además, de los clásicos equipos como Universitario de Deportes y Alianza Lima. Adicionalmente, hacen uso del espacio online; así como de promociones y sorpresas.

\subsection{Imagen Percibida}

\subsubsection{Mega Plaza}

La percepción que se tienen de MegaPlaza es de ser el primero, el pionero. El público de la investigación recordó que este mall fue el primero en brindarles esa oferta comercial que buscaban. Es evocado con aprecio por el público, por haber sido símbolo de progreso y modernidad en Lima Norte.

MegaPlaza es percibido como un centro comercial de fácil acceso y seguro al momento de ingresar. Seguro en el sentido de que no se tiene contacto cercano con los carros o el tráfico para ingresar, debido a que existe un puente peatonal que les soluciona la entrada.

Se crea la imagen de que MegaPlaza son variedad de tiendas, tiendas internacionales de renombre y shopping. Es más que nada un centro comercial para realizar compras, no tanto para pasear o ser un punto de entretenimiento.

Contrariamente, a este último resultado, MegaPlaza también es evocado como centro comercial familiar, al que se va a un segundo nivel a compartir momentos con los seres queridos, un tiempo no muy prolongado, tiempo en el que el niño juega en el centro de diversiones. Su target también está enfocado a la familia y existen elementos como el acuario que fortalecen la idea. A la vez, al momento de personificarlo se 
manifestó que es una mujer de mediana edad, algo "gordita" dedicada a su hijo, a su familia. Entonces, MegaPlaza, en la mente del consumidor, es la familia, el niño, los padres y los abuelos.

Las palabras que han sido asociadas a MegaPlaza, y que refuerzan la imagen anterior, son "tiendas, Coney Park, KFC, Saga Falabella, shows infantiles". A la vez, “desorden, antiguo, tráfico, congestión, mucha gente, saturados y estresados". Las primeras asociaciones como "tiendas y Saga Falabella" hacen claramente referencia a la oferta que ofrece MegaPlaza y a la actividad de compras que el público manifestó. Se refuerza que este mall es compras, tiendas. Las referencias hacia "Coney Park, KFC, shows infantiles" recuerda lugares o momentos en los que se pasa en compañía de la familia o que remiten al niño. Los adjetivos negativos usados por el público como "desorden, mucha gente, saturados" refiere a que MegaPlaza no tuvo un plan organizado antes de su construcción, lo cual se evidencia en un tenant mix desordenado con tiendas de diferentes rubros a los costados o al frente, que no deja la sensación de unidad en un mismo ambiente. Respecto a lo antiguo, tanto vinculado a la cantidad de años que tiene en Lima Norte en relación a su competencia, como por no innovar lo suficiente, hasta que llegó su nueva competencia. Por el lado de "saturados y mucha gente", se hace una evidencia clara a la cantidad de personas que visitan el centro comercial que al ser demasiados genera sensación de estrés y saturación. Los elementos como el tráfico, son externos al centro comercial, ya que la acumulación de carros no es dentro del mall sino a sus afueras; además, no es un elemento que pueda ser totalmente controlado por el centro comercial; incluso así, genera incomodidad en el público.

\subsubsection{Plaza Norte}

El centro comercial Plaza Norte es visualizado, por el público investigado, como un lugar para pasear. Este punto va acorde a las expectativas de los ejecutivos de convertir el centro comercial en una plaza donde el público pasea, se divierte y, al final, compra. Luego, los mensajes que la empresa emite ha logrado ser captado por el público. Existen elementos que refuerzan que las personas se sientan confortables al momento de pasear en el centro comercial como los sillones, piletas, luces y demás puntos de encuentros; adicionalmente, estas palabras han sido directamente asociadas a Plaza Norte como diferenciadores respecto a otros centros comerciales. Las imágenes 
de que Plaza Norte, no es solo comprar, sino es un espacio donde se pasea, se pasa momentos acompañados de amigos, pareja o familia, esta imagen de "plaza" está siendo captada por el inconsciente del público. El concepto de "plaza" trae consigo el sentimiento de tranquilidad. Tranquilidad porque ofrece espacios de diversión con la percepción de sentirse seguros, seguridad que estos tiempos se ha perdido; sin embargo, la seguridad como intangible se vuelve parte de la oferta comercial del centro comercial. La seguridad es fácilmente observada por la cantidad de personal de seguridad que existe dentro del centro comercial. Lo que quiere decir, que prefieren el espacio del centro comercial para pasear y distraerse frente a otros tipos de espacios para compartir, porque les permite distraerse con la percepción de estar seguros.

Otras imágenes mentales que se establecen en el público son El Gran Terminal Terrestre y el Teatro Plaza Norte. Determinados por el público como mayor innovación y exclusividad que diferencia a Plaza Norte de los demás malls, sobre todo, de la zona de Lima Norte. Ambos conceptos, como se ha escrito en capítulos anteriores, corresponden al tipo de innovación incremental que consiste en la mejora o modificación de algo ya existente. La idea de terminal terrestre y de teatro, existía antes de ser creado Plaza Norte; sin embargo, en el caso del terminal terrestre, no había sido llevada la idea a pertenecer a la oferta a un centro comercial. En el caso del teatro, solo el centro comercial Larcomar lo ofrece como parte de su tenant mix; sin embargo, este mall está enfocado en un público turista, por ende, contar con un teatro parece más lógico. En el caso de Lima Norte, ambos conceptos han impactado positivamente, debido a que al público objeto de la investigación, le agrada contar con un terminal terrestre formal, seguro, limpio, puntual, con las comodidades de un terrapuerto moderno. La anterior opción del público era el Terminal Terrestre de Fiori, que se encontraba a poca distancia de Plaza Norte, pero era un terrapuerto informal que no garantizaba viajes seguros ni horas exactas de partida. Respecto al teatro, causa sorpresa y sentimiento de orgullo, debido a que no necesitan moverse largas distancias para ver una obra teatral. Una exigencia del poblador de Lima Norte es que la oferta que desean no se encuentre a más de 30 minutos de distancia. Sin embargo, si antes el público deseaba optar por esta forma de entretenimiento debía dirigirse hasta, por lo general, el distrito de Miraflores donde se encuentra la mayor cantidad de ofertas teatrales.

Se ha valorado de Plaza Norte respecto a otros centros comerciales su modernidad e innovación. La innovación forma parte de la identidad de este centro comercial tanto en infraestructura, diseño, creación de conceptos, de ambientes y 
estrategias de marketing. El público ha logrado percibir que Plaza Norte es innovador, en el sentido, que crea nuevos conceptos y ambientes. Conceptos como Plaza Tradiciones, Villa de Papa Noel, capilla, entre otros, así como nuevos ambientes como boulevares o sala de lactancia, la vuelta al mundo en 8 minutos, etc. En este punto de innovación se señaló que existe una preocupación en los detalles dentro del centro comercial que, a la vez, son innovadores como las luces que proyectan el símbolo del centro comercial en el piso. Si bien el público considera a Plaza Norte más innovador que su competencia, no logran diferenciarlo en un primer momento de los demás centros comerciales, ya que mencionan que este centro comercial también es tiendas, shopping; sin embargo, cuando se profundiza un poco más sobre qué lo hace innovador y diferente señalan su terminal terrestre, teatro, Villa de Papa Noel, shows culturales, servicios de atención al ciudadano, que es un espacio para pasear. Que son justamente estos conceptos nuevos los que el centro comercial ofrece respecto a su competencia, que a la vez, son conceptos que ya han existido en otros espacios pero que no habían formado parte de una oferta comercial de los malls.

Las percepciones que tiene el público participante sobre Plaza Norte, ha generado respuestas a nivel cognitivo, afectivo y conductual. En el nivel cognitivo, Plaza Norte ha mejorado la expectativa de los pobladores sobre lo que significa ser un centro comercial moderno que brinda oferta tanto de tiendas, de servicios y entretenimiento. Ahora el público espera que un centro comercial no solo le brinden un espacio para comprar, sino que se convierta en un punto de encuentro para compartir. Que sea una "mini ciudad". En el nivel afectivo, existen actitudes positivas frente a Plaza Norte, lo cual se refuerza en la identificación con el centro comercial, ya que en el supuesto de que Plaza Norte dejara de operar en Lima Norte el público se sentiría triste y consideran que sería difícil encontrar una propuesta parecida. La identificación con el centro comercial también lleva al público a considerar que Plaza Norte es mejor en las experiencias que le brinda respecto a su competencia. Plaza Norte ha logrado trabajar el aspecto intangible de las experiencias memorables que se requiere para generar fidelidad a largo plazo. En el nivel conductual, se ha generado una adopción de los conceptos innovadores que ofrecen por lo que se genera una intención de comprar o uso de los servicios ofrecidos por el centro comercial.

Dos aspectos que no han logrado ser bien manejados por el centro comercial son el acceso y el target al que se dirige. El acceso, es dificultoso en sus principales entradas debido al caos de la Panamericana Norte o por el tráfico que se genera en la zona. 
Existen esfuerzos por mejorar el ingreso, debido a que el centro comercial cuenta con personal uniformado que ayuda a los peatones a cruzar las principales avenidas. Sin embargo, el tráfico de la zona no es un aspecto que pueda ser totalmente controlado por el centro comercial lo que genera malestar en el público que ingresa al centro comercial. Respecto al target existe discrepancia, debido a que el público al que desea captar el centro comercial en mayor medida se centra en la familia; sin embargo, elementos como la innovación, puntos de encuentro y entretenimiento hacen que asista mayormente público joven; así también, visualizan que Plaza Norte es para los jóvenes. Si se personifica al centro comercial sería una mujer en edad promedio de 25 años: mujer joven. Esta disparidad entre lo que se quiere atraer y lo se forma en la mente del consumidor, tendrá que ser evaluado por los mismos ejecutivos, quienes podrían adoptar como principal foco a los jóvenes.

Lo referido al uso de la escala de Likert se aprecia que existen mayores movimientos a favor de Plaza Norte sobre MegaPlaza con mayor cantidad de adjetivos positivos en palabras como innovador, joven, ágil, limpio, ambicioso y luminoso. En este sentido, se puede asegurar que existe una percepción más positiva de Plaza Norte sobre MegaPlaza por la cantidad de elementos y experiencia que le brinda, como ya antes se analizó. Es interesante observar que un centro comercial que fue objeto de orgullo en Lima Norte por ser el primero, pierda asociaciones positivas frente a una nueva oferta comercial que está llevando sus estrategias al camino de las experiencias y emociones: intangible. Queda claro que el camino de las emociones y de las experiencias en el retail de centros comerciales es la mejor opción para atraer público.

A modo de conclusiones generales del trabajo se desprende que a falta de espacios públicos donde los habitantes perciban seguridad para realizar las actividades de ocio, los centros comerciales, específicamente Plaza Norte, por su variedad de tiendas, servicios y ofertas innovadoras estaría siendo captada inconscientemente como una plaza pública. Pasear por las calles se ha vuelto una actividad insegura. El centro comercial brinda tangiblemente la opción de pasear, sentirse seguro y olvidar el espacio caótico que significa salir a la calle.

El centro comercial Plaza Norte ha logrado plantear la idea original de lo que es un centro comercial: réplica artificial de una plaza con sofisticación. Entendió las necesidades de su público ofreciéndoles variedad de tiendas, servicios planteándoles 
conceptos que están ligados a sus costumbres, acercándose así a crearles experiencias positivas con las que se identifican. Está trabajando positivamente el uso de los cinco sentidos para generar experiencias en su público. Así también, ha conseguido trabajar el aspecto intangible que es el que genera a largo plazo la lealtad de marca que todos los productos o servicios anhelan. Lo recordado como puntos de exclusividad en Plaza Norte son su Gran Terminal Terrestre y su Teatro Plaza Norte.

MegaPlaza ha logrado permanecer en el sentimiento de evocación de una cálida niñez y sentimientos de familia. Sin embargo, las actividades de lo que más hace el público está vinculado a un aspecto material: hacer shopping. Por tanto, en términos emocionales está perdiendo lugar, en el público objeto de la investigación, y está pasando a ser un lugar para realizar una actividad puntual: compras. Pierde lugar en el aspecto emocional, debido a la gran cantidad de personas que asiste, lo que termina generando una compra o actividad rápida.

El estudio realizado se ha centrado en las percepciones que el público investigado señaló en el 2014 con resultados positivos y mejores asociaciones de Plaza Norte frente a MegaPlaza; sin embargo, un trabajo futuro sería medir si en realidad todos los elementos que están haciendo diferenciar a Plaza Norte de los demás centros comerciales y, sobre todo, de su competencia directa MegaPlaza ha logrado conseguir a futuro fidelidad y lealtad de marca. Por otro lado, también es interesante observar como a falta de espacios públicos, en nuestra ciudad, donde existe la necesidad de compartir espacios con la familia o los amigos se han buscado opciones como los centros comerciales para entretenerse y ahora son los mismos centros comerciales quienes desean ofrecen esa oferta comercial. Se torna interesante estudiar más a fondo los comportamientos de las personas dentro de los centros comerciales en Lima y si realmente los centros comerciales están siendo la opción de entretenimiento y plazas que le falta a Lima. 


\section{REFERENCIAS}

Arellano Marketing. (2012). Retail peruano: centros comerciales. Lima, Perú: Arellano Marketing.

Arellano Marketing. (2014). Estudios marcas 2014 [recurso electrónico]: categoría centros comerciales (Informe Final). Lima, Perú: Arellano Marketing.

Arellano, R. (2002). Comportamiento del consumidor: Enfoque América Latina. México: McGraw-Hill Interamericana.

Arellano, R. (04 de 10 de 2013). Encontrando oro en el desierto. Recuperado el 25 de 10 de 2014, de Arellano Marketing: http://www.arellanomarketing.com/inicio/encontrandooro-en-el-desierto/

Benavides, E. (s.f.). Claves del retail visión 2013-2015: Retos para el marketing de los centros comerciales. Recuperado el 10 de seriembre de 2014, de Claves del retail: http://www.clavesdelretail.com/wpcontent/uploads/2015/10/claves\%20del\%20retail.pdf

Boulding, K. (1956). The Image: Knowledge in Life and Society. United States of America: University of Michigan Press.

Capriotti, P. (2009). Branding corporativo: Fundamentos para la gestión estratégica de la identidad corporativa (6ㅇ edición ed.). Santiago, Chile: Business School Universidad Mayor.

El Comercio. (13 de abril de 2015). El Comercio Economía: la imparable expansión de lo centros comerciales en el país. Recuperado el 10 de mayo de 2016, de El Comercio: http://elcomercio.pe/economia/peru/imparable-expansion-centros-comerciales-paisnoticia-1803728

Kato, S. (24 de 09 de 2013). Wong: la filosofía para el éxito. Recuperado el 2014, de Pymex: https://pymex.pe/suplementos/negocios-geniales/wong-la-filosofia-para-el-exito/

León-Gambetta, Á. (2016). Presentación del curso marketing de centros comerciales e hipermercados. Lima: Universidad de Lima.

López, L. (1999). Centros comerciales: Espacios que navegan entre la realidad y la ficción. México: Nuestro Tiempo.

Luecke, R. (2004). Desarrollar la gestión de la creatividad y de la innovación. Barcelona: Deusto.

Mayorga, D., Araujo, P., \& Schwalb, M. M. (2005). Las mejores prácticas del marketing: casos ganadores de los premios Effie 2004. Recuperado el 27 de 09 de 2014, de Universidad del Pacífico:

http://repositorio.up.edu.pe/bitstream/handle/11354/217/Effie2005.pdf?sequence=4

Orrego Penagos, L. (2011). Rumbo al Bicentenario. Recuperado el 20 de abril de 2014, de Blog de Juan Luis Orrego Penagos. Historia del Perú, América Latina y el mundo: Historia de los centros comerciales de Lima: 
http://blog.pucp.edu.pe/blog/juanluisorrego/2010/05/16/historia-de-los-centroscomerciales-de-lima-2/

Petitjean, M. (2013). C.C. Plaza Norte (Arquitectura \& Diseño) - Versión Español. Recuperado el 2014, de Youtube: https://vimeo.com/64170439

Pintado, T., \& Sánchez, J. (2013). Imagen Corporativa: Influencia en la gestión empresarial. Madrid, España: Esic.

Regalado, O., Fuentes, C., Aguirre, G., García, N., Miu, R., \& Vallejo, R. (2009). Factores críticos de éxito en los centros comerciales de Lima Metropolitana y el Callao. Recuperado el 20 de 10 de 2014, de Esan:

http://www.esan.edu.pe/publicaciones/Descargue\%20el\%20documento\%20completo -.pdf

Rico, R. R., \& Evaristo, D. (2003). Retail Marketing: El nuevo marketing para el negocio minorista. Buenos Aires: Pearson Education.

Rivera Camino, J., Arellano Cueva, R., \& Molera Ayala, V. (2013). Conducta del consumidor: estrategias y políticas aplicadas al marketing (3o edición ed.). Madrid, España: Esic.

Solomon, M. R. (2008). Comportamiento del consumidor. México: Pearson Prentice Hall.

Stanton, W., Etzel, M., \& Walker, B. (2007). Fundamentos de Marketing. México: Mc Graw Hill Interamericana.

Stephens, D. (2013). The Retail Revival: Reimagining business for the new age of consumerism. Canada: Willey.

Underhill, P. (2004). Call of the Mall: The Geography of Shopping. New York: Simon \& Schuster Paperbacks. 


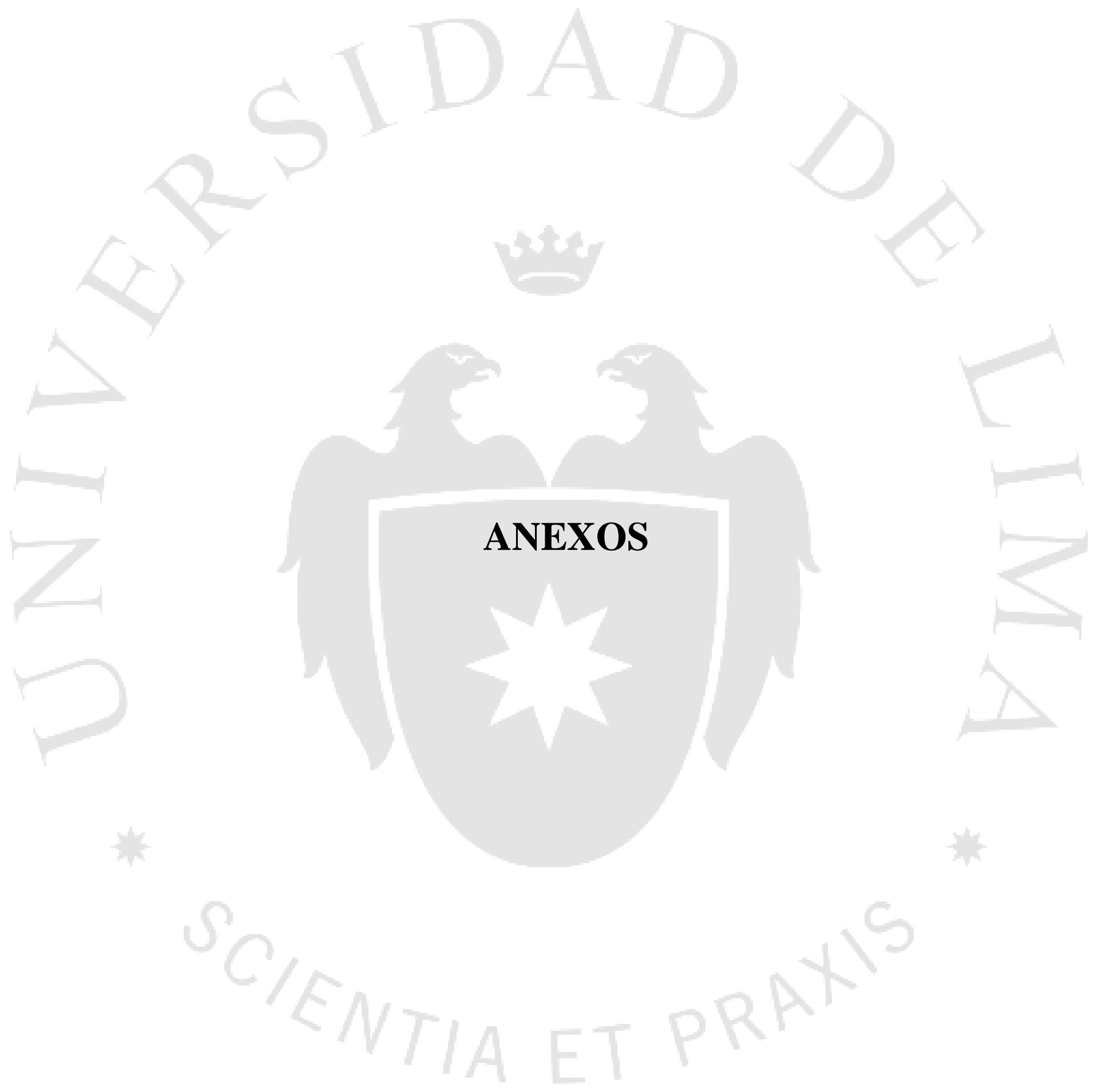




\section{ANEXO 1: FICHA TÉCNICA ENTREVISTA EJECUTIVOS CENTROS COMERCIALES}

\begin{tabular}{|c|c|}
\hline Técnica & Entrevista en profundidad \\
\hline Entrevistados & $\begin{array}{l}\text { Plaza Norte: } \\
\text { Analista de Marketing de Plaza } \\
\text { Norte - Juan Carrillo } \\
\text { Gerente de Centros Comerciales e } \\
\text { Inmobiliaria de la Corporación E. } \\
\text { Wong - Edgar Callo } \\
\text { MegaPlaza } \\
\text { Jefa del Área de Marketing de } \\
\text { MegaPlaza - Jenny Vega }\end{array}$ \\
\hline Duración promedio & 45 minutos \\
\hline Lugares de las entrevistas & Plaza Norte, MegaPlaza \\
\hline Fecha de campo & Setiembre - Noviembre del 2014 \\
\hline
\end{tabular}

\section{ANEXO 2: FICHA TÉCNICA FOCUS GROUP}

\begin{tabular}{|c|c|c|c|c|}
\hline FICHA TÉCNICA & GRUPO 1 & GRUPO 2 & GRUPO 3 & GRUPO 4 \\
\hline Género & Mixto & Mixto & Mixto & Mixto \\
\hline Edad Promedio & 25 & 26 & 23 & 19 \\
\hline Lugar de residencia & $\begin{array}{l}\text { Los Olivos, San } \\
\text { Martín, } \\
\text { Independencia }\end{array}$ & $\begin{array}{l}\text { San Martín de Porres, } \\
\text { Los Olivos, Comas }\end{array}$ & $\begin{array}{l}\text { Carabayllo, San Martín } \\
\text { de Porres, Callao }\end{array}$ & $\begin{array}{c}\text { Independencia, San } \\
\text { Martín de Porres, Los } \\
\text { Olivos }\end{array}$ \\
\hline Asistencia a CC. & $\begin{array}{c}\text { Plaza Norte, } \\
\text { MegaPlaza, Real } \\
\text { Plaza Centro Cív }\end{array}$ & $\begin{array}{c}\text { Plaza Norte, MegaPlaza, } \\
\text { Plaza San Miguel }\end{array}$ & $\begin{array}{c}\text { Mall Aventura Callao, } \\
\text { Plaza Norte, MegaPlaza, } \\
\text { Real Plaza Centro Cívico }\end{array}$ & $\begin{array}{c}\text { MegaPlaza, Plaza Norte, } \\
\text { Plaza San Miguel, Real } \\
\text { Plaza Centro Cívico }\end{array}$ \\
\hline Reclutamiento & CC. Plaza Norte & CC. Plaza Norte & CC. Plaza Norte & CC. Plaza Norte \\
\hline Lugar de realización & Starbucks & Starbucks & Pinkberry & Starbucks \\
\hline Fecha de Campo & $\begin{array}{c}12 \text { de noviembre } \\
2014\end{array}$ & 14 de noviembre 2014 & 18 de noviembre 2014 & 21 de noviembre 2014 \\
\hline
\end{tabular}




\section{ANEXO 3: FICHA TÉCNICA ENCUESTA}

\begin{tabular}{|c|c|}
\hline Técnica & Encuesta presencial \\
\hline Aplicación & Individual \\
\hline Tamaño de la muestra & 110 encuestas \\
\hline Finalidad & Medir la imagen y percepción del centro comercial Plaza Norte \\
\hline Población & Hombres y mujeres de 18 a 35 años que residen en Lima Norte \\
\hline Duración & Sín límite de tiempo, 4 minutos aproximadamente \\
\hline Lugar de realización & Centro comercial Plaza Norte \\
\hline Fecha de campo & $24-28$ de noviembre del 2014 \\
\hline
\end{tabular}

\section{ANEXO 4: RESUMEN EJECUTIVO ENCUESTA}

\begin{tabular}{|c|c|}
\hline PRESENTACIÓN & $\begin{array}{l}\text { La encuesta pretende conocer las emociones, recuerdos y asociaciones que el público tiene sobre el CC. } \\
\text { Plaza Norte llegando a una mayor cantidad de personas. Además, conocer la asociación de adjetivos tanto } \\
\text { del CC. Plaza Norte como del CC. MegaPlaza. La información se recolectó a través de encuestas personales } \\
\text { a hombres y mujeres de } 18 \text { a } 35 \text { años que viven en Lima Norte. }\end{array}$ \\
\hline $\begin{array}{l}\text { PERFIL } \\
\text { DEMOGRÁFICO }\end{array}$ & $\begin{array}{l}\text { El rango de edad del público encuestado que más asistió al centro comercial Plaza Norte fue de } 18 \text { a } 23 \text { años } \\
\text { con un } 67 \% \text {, seguido del rango de } 24 \text { a } 29 \text { años con un } 25 \% \text {. El rango de } 30 \text { a } 35 \text { años solo fue un } 8 \% \text {. El } \\
\text { público fue mayormente masculino con } 56 \% \text { frente al femenino } 44 \% \text {. El } 54 \% \text { del público era estudiante de } \\
\text { universidad, el } 23 \% \text { trabajador profesional. El } 11 \% \text { trabajador independiente. Provenían, en mayor medida, de } \\
\text { los distritos de Los Olivos, San Martín de Porres y Comas. La asistencia al centro comercial más frecuente } \\
\text { fue de } 1 \text { a } 4 \text { veces al mes con } 56 \% \text {. El } 71 \% \text { señaló que asiste con amigos y más del } 50 \% \text { lo hace con la } \\
\text { familia. }\end{array}$ \\
\hline $\begin{array}{l}\text { SERVICIOS } \\
\text { RECORDADOS AL } \\
\text { INSTANTE Y ÚNICOS }\end{array}$ & $\begin{array}{l}\text { Los servicios que se le viene a la mente al público, al instante, de Plaza Norte fueron tiendas, comida, } \\
\text { conceptos ancla como: terminal terrestre, MAC, Expomotor. Los elementos que perciben como únicos fueron } \\
\text { tiendas especializadas, terminal terrestre y teatro. Seguido de lugares de entretenimiento. }\end{array}$ \\
\hline $\begin{array}{l}\text { ELEMENTOS } \\
\text { OBSERVADOS Y } \\
\text { VALORADOS }\end{array}$ & $\begin{array}{l}\text { Los elementos más importantes que recuerdan haber visto fueron teatro } 57 \% \text {, Expomotor } 44 \% \text {, Banco de la } \\
\text { Nación } 40 \% \text {, MAC, } 30 \% \text {, museo } 23 \% \text {, entre otros. Además, los elementos más valorados fueron variedad de } \\
\text { tiendas } 74 \% \text {, variedad de servicios } 44 \% \text {, limpieza } 43 \% \text {. }\end{array}$ \\
\hline $\begin{array}{l}\text { ACCESO Y CIERRE } \\
\text { DE PLAZA NORTE }\end{array}$ & $\begin{array}{l}\text { El ingreso a Plaza Norte es considerado fácil } 74 \% \text { y difícil en } 26 \% \text { por el público participante. En el supuesto } \\
\text { de que el centro comercial dejara de operar en Lima Norte el público señalo que se sentiria triste } 66 \% \text {, le da } \\
\text { igual } 33 \% \text {, contento } 1 \% \text {. }\end{array}$ \\
\hline
\end{tabular}




\section{ANEXO 5: GUÍA PREGUNTAS EJECUTIVOS CENTROS COMERCIALES}

\section{GUIA DE PREGUNTAS EJECUTIVOS CENTROS COMERCIALES}

\section{Identidad Corporativa}

a. Identidad

- ¿Qué valores como corporación manejan?

- ¿Cuál es la imagen que quieren proyectar como centro comercial?

- ¿Cuál es la idea o ideas claves que quieren transmitir al público que los diferencie de los demás?

- ¿Consideran que el público está captando este mensaje? ¿De qué manera lo está haciendo?

b. Estrategias Utilizadas

- ¿Qué estrategias están utilizando para diferenciarse de los demás centros comerciales?

- ¿A través de qué medios lo hacen?

- ¿Qué están haciendo para fidelizar a su consumidores?

- ¿Cuál es su público objetivo?

- ¿Qué tipos de experiencias desean brindarle al público?

\section{Sobre la competencia}

- ¿Cómo se configura la competencia, ha ido cambiando en el tiempo o se ha mantenido?

- ¿Cuál sería su competencia directa?

- ¿Qué creen que desea transmitir la competencia?

3. Futuro

- ¿Cómo ha ido evolucionando el centro comercial desde sus inicios hasta el dia de hoy?

- ¿Cómo se visualizan en el futuro? ¿Cuál sería la proyección a futuro? 


\title{
ANEXO 6: GUÍA FOCUS GROUP
}

Edad:

\author{
GUIA FOCUS GROUP
}

Distrito:

\section{Centros Comerciales}

- ¿Qué centros comerciales visitan o han visitado?

- ¿Qué es lo que más les gusta de estos centros comerciales?

- ¿Cuál de estos consideran el mejor centro comercial que les brinda mejores experiencias? ¿Por qué?

- ¿Cuántas veces al mes suelen asistir a los centros comerciales?

\section{Centros Comerciales MegaPlaza y Plaza Norte}

- ¿Qué es lo primero que se les viene a la mente o recuerdan cuando les menciono MegaPlaza?

- ¿Qué es lo primero que se les viene a la mente o recuerdan cuando les menciono Plaza Norte?

- ¿Qué diferencias encuentran entre MegaPlazza y Plaza Norte? ¿Por qué?

- ¿Qué es lo que más les gusta y valoran de MegaPlaza y de Plaza Norte? (Infraestructura, espacio, promociones, servicio, etc.?)

- ¿En qué centro comercial se sienten más a gusto?

- ¿Cuál de los dos centros comerciales sientes que les brinda una mejor experiencia? ¿Por qué?

- ¿Qué tipo de experiencia les brinda MegaPlaza y Plaza Norte?

- ¿Cuál de los dos centros comerciales les sorprende más cada vez que van de visita o de compra? ¿Por qué?

- ¿A quiénes crees que va dirigido cada centro comercial? (públicos, nse, edad, género)

- ¿Si MegaPlaza fuera una persona, cómo sería? (años, edad, qué hace, a que se dedica?)

- ¿Si Plaza Norte fuera una persona, cómo sería? (años, edad, qué hace, a que se dedica?)

\section{Centro Comercial Plaza Norte}

- ¿Vienen continuamente a Plaza Norte o solo a veces? (al mes cuántas veces) ¿En qué ocasionen vienen?

- ¿Cómo consideran el ingreso a Plaza Norte? (ordenado, desordenado, seguro, no seguro, fácil, dificil)

- ¿Cuándo vienen a Plaza Norte, qué actividades suelen hacer? (pasear, comer, etc.) 
- ¿Sus amigos y familiares suelen frecuentar el centro comercial o solo son ustedes quienes asisten a este centro comercial?

- ¿Es parte de sus conversaciones hablar del centro comercial?

- ¿Comparten momentos de sus visitas al centro comercial? ¿Mediante qué medios?

- ¿Por qué medios se enteran de las novedades de Plaza Norte?

- ¿Conocen e interactúan (comentan, sugieren, dan like) a las páginas oficiales del centro comercial?

- ¿Qué cosas consideran que son únicas de este centro comercial que no hayan visto en otros centros comerciales?

- ¿Cómo se sienten cuando están dentro del centro comercial?

- ¿Qué cosas son las que más les gusta de este centro comercial?

- ¿Qué tipos de experiencias les ha brindado el centro comercial? Alguna que recuerden?

- ¿Qué significa y es para ustedes Plaza Norte?

- ¿Cómo describirían al centro comercial? ¿Qué adjetivos le pondrian?

- ¿Alguna vez se han sorprendido por las cosas que ven en el centro comercial? ¿Como cuáles?

- En una sola palabra cómo definirian al centro comercial Plaza Norte

- Si tuvieran que asociar una emoción relacionada al centro comercial, ¿cuál mencionarian?

- ¿Qué sentirian si les digo que Plaza Norte ya no va a operar más en Lima Norte?

- ¿Si el centro comercial les regala un collar o algún obsequio con el logo del centro comercial lo utilizarían?

Muchas gracias, la información proporcionada será muy útil. 
ANEXO 7: CUESTIONARIO PLAZA NORTE

CUESTIONARIO PLAZA NORTE

1. Edad:

a. $18-23$

b. $24-29$

c. $30=35$

2. Género:

a. Femenino

b. Masculino

3. Distrito:

4. Ocupación:
a. Estudiante - Universidad
d. Trabajador Independiente
b. Estudiante - Instituto
e. Otro(especifique):

5. ¿Con qué frecuencia asiste al Centro Comercial Plaza Norte?
a. Entre 1 y 4 veces al mes
b. Entre 5 y 8 veces al mes
c. Más de 8 veces al mes

6. ¿Con quiénes asiste al centro comercial?

$\square$ Solo
$\square$ Familia
$\square$ Amigos
$\square$ Otro (especifique):

7. ¿Qué servicios recuerda en estos momentos de Plaza Norte?, escriba los que recuerda.

8. ¿Qué considera único de Plaza Norte que no haya visto en otro centro comercial?

9. De los siguientes servicios, ¿cuál de ellos conoce o recuerda haber visto?

$\square$ Teatro
$\square$ Museo
$\square$ Capilla
$\square$ Sala de lactancia
$\square$ Plaza Tradiciones
$\square$ MAC

10. ¿Qué elementos valora de Plaza Norte?
a. Variedad de tiendas
b. Variedad de servicios
c. Orden
d. Limpieza

\footnotetext{
11. En Plaza Norte me siento:

$\square$ Seguro
$\square$ Relajado
$\square$ Entretenido
$\square$ Alegre
$\square$ Confortable
}

(Marque todas las que considere)

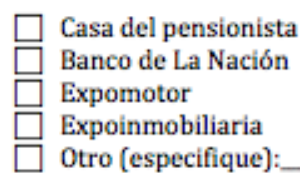

(Marque todas las que considere)

e. Amplitud de espacios

f. Puntos de encuentro

g. Otro (especifique):
(Marque todas las que considere)

$\square$ Aburrido
$\square$ Estresado
$\square$ Sorprendido
$\square$ Otro(especifique)


12. Ingresar a Plaza Norte es:

(Marque solo una)
a. Seguro
b. No seguro

13. A continuación se presenta una serie de adjetivos opuestos. Señale con " $\mathrm{X}$ " el número que exprese mejor lo que piensa de Plaza Norte.

Ejemplo:

\begin{tabular}{|l|l|l|l|l|l|l|}
\hline & 1 & 2 & 3 & 4 & 5 & \\
\hline Conservador & & & & & $X$ & Innovador \\
\hline
\end{tabular}

Significa que Plaza Norte es bastante innovador

Ahora marque usted:

\begin{tabular}{|l|l|l|l|l|l|l|}
\hline & 1 & 2 & 3 & 4 & 5 & \\
\hline Conservador & & & & & & Innovador \\
\hline Viejo & & & & & & Joven \\
\hline Lento & & & & & & Ágil \\
\hline Antiguo & & & & & & Moderno \\
\hline Barato & & & & & & Caro \\
\hline Sucio & & & & & & Limpio \\
\hline Desinteresado & & & & & & Ambicioso \\
\hline Oscuro & & & & & & Luminoso \\
\hline
\end{tabular}

14. A continuación se presenta una serie de adjetivos opuestos. Señale con " $\mathrm{X}$ " el número que exprese mejor lo que piensa de MegaPlaza.

\begin{tabular}{|l|l|l|l|l|l|l|}
\hline & 1 & 2 & 3 & 4 & 5 & \\
\hline Conservador & & & & & & Innovador \\
\hline Viejo & & & & & & Joven \\
\hline Lento & & & & & & Ágil \\
\hline Antiguo & & & & & & Moderno \\
\hline Barato & & & & & & Caro \\
\hline Sucio & & & & & & Limpio \\
\hline Desinteresado & & & & & & Ambicioso \\
\hline Oscuro & & & & & & Luminoso \\
\hline
\end{tabular}

15. ¿Cuál es la principal ventaja competitiva de Plaza Norte frente a MegaPlaza? (Maque todas las que considere)
a. Acceso
b. Variedad de servicios
e. Comodidad
c. Variedad de tiendas
f. Luminosidad
d. Seguridad
g. Otro:

16. Si Plaza Norte dejara de operar en Lima Norte, me sentiría
a. Triste
b. Me da igual
c. Contento

(Marque solo una) 


\section{ANEXO 8: SERVICIOS QUE RECUERDA}

9 De los siguientes servicios, ¿cuál de ellos conoce o recuerda haber visto? (Marque todas las que considere)

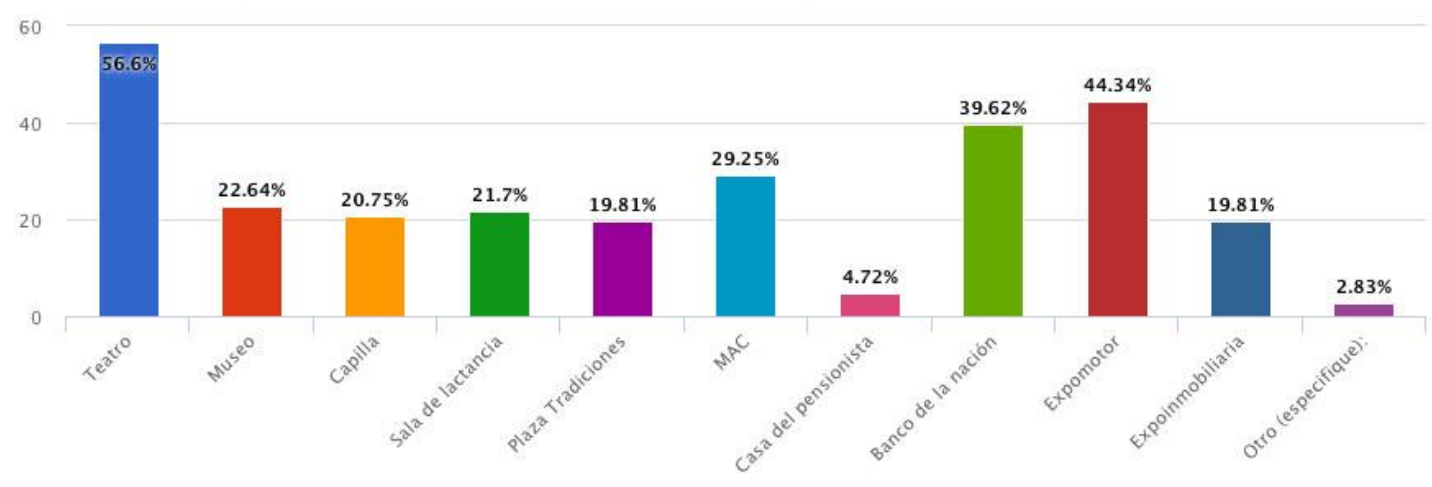

\section{ANEXO 9: ELEMENTOS QUE VALORA}

10 ¿Qué elementos valora de Plaza Norte? (Marque todas las que considere)

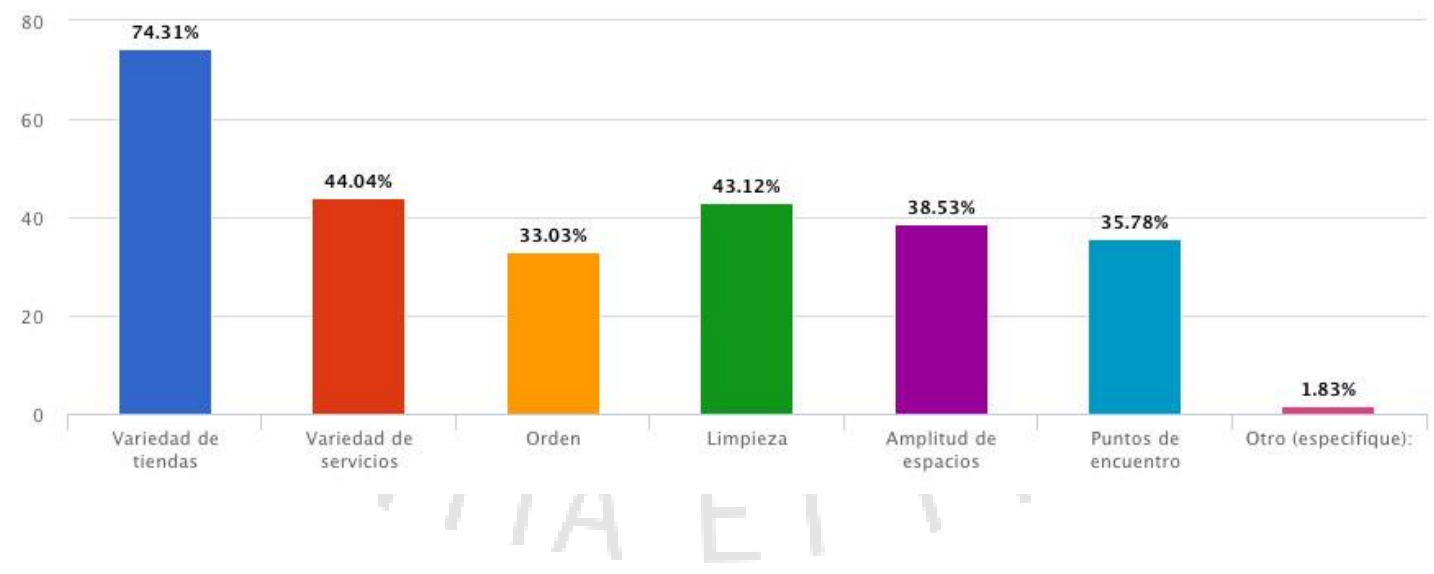




\section{ANEXO 10: RESPUESTA DIFERENCIAL SEMÁNTICO}

13. A continuación se presenta una serie de adjetivos opuestos. Señale con una " $X$ " el número que exprese mejor lo que piensa de Plaza Norte.

\begin{tabular}{|c|r|r|r|r|r|c|}
\hline & \multicolumn{1}{|c|}{1} & \multicolumn{1}{|c|}{2} & \multicolumn{1}{c|}{3} & \multicolumn{1}{c|}{4} & \multicolumn{1}{c|}{5} & \\
\hline Conservador & $4,3 \%$ & $7,53 \%$ & $25,81 \%$ & $37,63 \%$ & $24,73 \%$ & Innovador \\
\hline Viejo & $2,33 \%$ & $8,14 \%$ & $24,42 \%$ & $40,7 \%$ & $24,42 \%$ & Joven \\
\hline Lento & $2,35 \%$ & $8,24 \%$ & $28,24 \%$ & $38,82 \%$ & $22,35 \%$ & Ágil \\
\hline Antiguo & $2,33 \%$ & $3,49 \%$ & $17,44 \%$ & $47,67 \%$ & $29,07 \%$ & Modemo \\
\hline Barato & $3,53 \%$ & $7,06 \%$ & $55,29 \%$ & $22,35 \%$ & $11,76 \%$ & Caro \\
\hline Sucio & $3,53 \%$ & $5,88 \%$ & $16,47 \%$ & $41,18 \%$ & $32,94 \%$ & Limpio \\
\hline Desinteresado & $6,02 \%$ & $6,02 \%$ & $34,94 \%$ & $33,73 \%$ & $19,28 \%$ & Ambicioso \\
\hline Oscuro & $2,38 \%$ & $3,57 \%$ & $13,1 \%$ & $39,29 \%$ & $41,67 \%$ & Luminoso \\
\hline
\end{tabular}

14. A continuación se presenta una serie de adjetivos opuestos. Señale con una " $X$ " el número que exprese mejor lo que piensa de MegaPlaza.

\begin{tabular}{|c|r|r|r|r|r|c|}
\hline & \multicolumn{1}{|c|}{1} & \multicolumn{1}{|c|}{2} & \multicolumn{1}{c|}{3} & \multicolumn{1}{c|}{4} & \multicolumn{1}{c|}{5} & \\
\hline Conservador & $4,7 \%$ & $17,65 \%$ & $32,94 \%$ & $29,41 \%$ & $15,29 \%$ & Innovador \\
\hline Viejo & $12,5 \%$ & $15,91 \%$ & $26,14 \%$ & $34,09 \%$ & $11,36 \%$ & Joven \\
\hline Lento & $10,71 \%$ & $11,9 \%$ & $40,48 \%$ & $25 \%$ & $11,9 \%$ & Ágil \\
\hline Antiguo & $8,33 \%$ & $10,71 \%$ & $36,9 \%$ & $32,14 \%$ & $11,9 \%$ & Modemo \\
\hline Barato & $8,33 \%$ & $11,9 \%$ & $38,1 \%$ & $28,57 \%$ & $13,1 \%$ & Caro \\
\hline Sucio & $11,9 \%$ & $10,71 \%$ & $30,95 \%$ & $30,95 \%$ & $15,48 \%$ & Limpio \\
\hline Desinteresado & $8,75 \%$ & $10 \%$ & $35 \%$ & $32,5 \%$ & $13,75 \%$ & Ambicioso \\
\hline Oscuro & $11,11 \%$ & $5,56 \%$ & $25 \%$ & $38,89 \%$ & $19,44 \%$ & Luminoso \\
\hline
\end{tabular}

